\section{SUBROGADOS Y HACINAMIENTO CARCELARIO. RESPUESTA DEL LEGISLADOR DEL AÑO 2014 FRENTE A LA SITUACIÓN CARCELARIA EN COLOMBIA*}

\author{
SUBROGATED AND PRISON OVERCROWDING. \\ RESPONSE FROM THE LEGISLATOR OF YEAR \\ 2014 ABOUT THE PRISON SITUATION IN \\ COLOMBIA
} SUB-ROGADO E SUPERLOTAÇÃO DE PRISÃO.
RESPOSTA DO LEGISLADOR DO ANO DE 2014 Âं
SITUAÇÃO DE PRISÃO NA COLÔMBIA

\section{RESUMEN}

El presente texto analizó, en profundidad, la reforma introducida por la ley 1709 de 2014 a los Códigos Penal y Penitenciario y Carcelario colombianos, estudiando en especial la figura de los subrogados penales y la fluctuación de los requisitos exigidos para la concesión de los mismos, así como la aplicación que los operadores judiciales les han dado, frente al tránsito de legislación. Para esto, se realizó trabajo de campo tanto en los Juzgados de Ejecución de Penas y Medidas de Seguridad de Bogotá, como en otros despachos judiciales, obteniendo las providencias que reposan en sus archivos y entrevistando a los funcionarios encargados de adoptar estas decisiones. Esta labor permitió la construcción de algunos postulados descriptivos, así como de otros críticos, con base en la entrada en vigencia de esta norma jurídica.

\footnotetext{
* Artículo de reflexión realizado por los autores en desarrollo de su labor al interior del Grupo de Prisiones de la Universidad de los Andes y la culminación del trabajo de campo en los Juzgados de Ejecución de Penas y Medidas de Seguridad de Bogotá y en la Cárcel La Modelo de la ciudad de Bogotá.

a. Abogada de la Universidad de los Andes, Miembro del Grupo de Prisiones, Asociada de Holland \& Knight Colombia

b. Abogado, especialista y magister en derecho penal de la Universidad Libre. Especialista en derecho constitucional y en derecho administrativo de la Universidad del Rosario. Candidato a doctor en Derecho de la Universidad de los Andes. Coordinador del Grupo de Prisiones de la misma Universidad y Conjuez del Tribunal Superior de Florencia (Caquetá) - Sala Penal -
}

Juliana Archila Villalobos ${ }^{a}$ j.archila2529@uniandes.edu.co Norberto Hernández Jiménez n.hernandez29@uniandes.edu.co Fecha de recepción: 17 de noviembre de 2014 Fecha de revisión: 14 de marzo de 2015 Fecha de aceptación: 21 de marzo de 2015

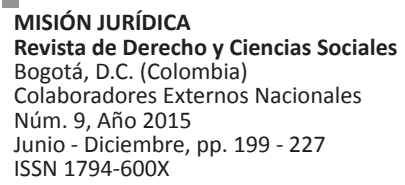




\section{PALABRAS CLAVE}

Libertad condicional, prisión domiciliaria, suspensión condicional de la ejecución de la pena.

\begin{abstract}
This text analyzed, in depth, the reform introduced by the 1709 law of 2014 to the Criminal Code, Penitentiary and for Prison of Colombia, studying especially the figure of penal subrogated and the fluctuation of the requirements demanded for their concession, as well as the application that the judicial operators have given, with respect to the transit of legislation. For this, it has been done a field work among the Courts of Execution and Security Measures of Bogotá, as well as in other judicial offices, obtaining the rulings that rest in their archives and interviewing the civil servants in charge of adopting these decisions. This investigation allowed the construction of some descriptive postulates, as well as some others questioning, based on the take effect of this legal norm.
\end{abstract}

\section{KEY WORDS}

Conditional Release, Home Detention, Conditional Suspension of Sentence.

\section{RESUMO}

Este texto analisou, em profundidade, a reforma introduzida pela Lei 1.709, de 2014, nos Códigos Penais e Penitenciários, e Prisionais da Colômbia, estudando, em particular, a figura do regime aberto para a pena privativa de liberdade e a oscilação dos requisitos para a sua concessão, bem como a aplicação dada pelos operadores de execução judicial contra a passagem da legislação. Para isso, foi realizado trabalho de campo, tanto nos Tribunais de Execução de Penas e Medidas de Segurança de Bogotá, como em outros cargos judiciais, obtendo-se as medidas que constam de seus arquivos e entrevistando os funcionários responsáveis por essas decisões. Este trabalho permitiu a construção de alguns postulados descritivos, assim como outros críticos, com base na promulgação desta lei.

\section{PALAVRAS-CHAVE}

Liberdade condicional; prisão domiciliar; suspensão condicional da execução da sentença.

\section{INTRODUCCIÓN}

La legislación penal colombiana consagra algunos mecanismos sustitutivos de la pena de prisión (subrogados penales) ${ }^{1}$ que operan como dispositivos que permiten cambiar o mutar la internación en establecimiento penitenciario por la alternativa de no purgar la pena, purgarla en el lugar de residencia del condenado/condenada o purgar un tiempo determinado en prisión y poder salir de ella en un lapso inferior a la pena definitiva impuesta. Los subrogados penales son una prerrogativa que tienen los condenados y se fundamentan en la "humanización del derecho penal y la motivación para la resocialización del delincuente"2.

La naturaleza jurídica de los subrogados penales se ha discutido de antaño y el debate gira sobre dos ejes centrales: si estos son sustitutivos de la pena o por el contrario constituyen un fin mismo de aquella ${ }^{3}$. La redacción del legislador colombiano determina que los subrogados penales tienen carácter sustitutivo. Ahora, si bien los subrogados penales tienen un origen positivista, donde se tiene en cuenta la peligrosidad del condenado, "es quizá la normatividad que ha sabido sostenerse dentro del marco de la nueva perspectiva filosófica del nuevo Código Penal, pues constituye uno de los mecanismos más sanos conquistados por el derecho penal liberal" ${ }^{4}$. Así pues, para realizar la aplicación de los subrogados, el operador jurídico debe leer la norma de la mano de un criterio culpabilista que a la luz de la Constitución del 91 "propende por un derecho penal de acto" ${ }^{5}$.

1. No se hará referencia en este texto al arresto de fin de semana convertible en arresto ininterrumpido, como sustitutivo de la pena de multa (artículo 36 del Código Penal), por tener esta última un carácter pecuniario y cuyo fin no es la privación de la libertad.

2. Sentencia C-425 de 2008, M.P. Marco Gerardo Monroy Cabra. Nota: Las referencias que dentro de este texto se hagan a las providencias precedidas por los literales $C$ - y T-corresponden a sentencias de constitucionalidad $y$ de tutela, respectivamente, proferidas por la Corte Constitucional, organismo perteneciente a la Rama Judicial del Poder Público en Colombia, Corporación a la que el constituyente primario le confió la guarda de la integridad y supremacía de la Carta Política. Las siglas M.P. se utilizan para designar al Magistrado que elaboró la ponencia o el proyecto de fallo.

3. RUIZ, Hoover, Equitipicidad, culpabilidad, preterintención y subrogados penales, Bogotá: Ediciones Jurídicas Gustavo Ibáñez, 1997, p. 222.

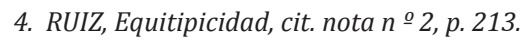

5. RUIZ, Equitipicidad, cit. nota $n^{\circ} 2$, p. 213 . 
Tradicionalmente, dentro de la cultura jurídico penal colombiana, se han concebido como subrogados penales: 1) la condena de ejecución condicional (hoy suspensión condicional de la ejecución de la pena) y 2) la libertad condicional ${ }^{6}$ . Sin embargo, dentro de esta tipología también puede consagrase la prisión domiciliaria ${ }^{7}$, así como una modalidad de prisión domiciliaria establecida por el legislador del año 2000, cuyos beneficiarios son todas las personas que ostenten la calidad de madre o padre ${ }^{9}$ cabeza de familia. Estos mecanismos son analizados en la fase de conocimiento (suspensión condicional de la ejecución de la pena y prisión domiciliaria) y durante la fase de ejecución del proceso penal ${ }^{10}$.

Con la entrada en vigencia de la Ley 1709 de $2014^{11}$, se introducen modificaciones en lo referente al tema de los subrogados penales consagrados en el Código Penal. De manera general, el propósito de esta norma es hacerle frente a la crisis del sistema penitenciario y carcelario por la cual atraviesa Colombia, desde hace ya varios años.

\section{Cfr. Sentencia C-679/98, M.P. Carlos Gaviria Díaz.}

7. Cfr. Radicados 31531 (08-07-09), M.P. Yesid Ramírez Bastidas y 31568 (28-10-09), M.P. Alfredo Gómez Quintero [COLOMBIA, Rama Judicial del Poder Público, Corte Suprema de Justicia - Sala de Casación Penal].

\section{Cfr. Sentencia C-184/03, M.P. Manuel Jose Cepeda Espinosa.}

9. Cfr. Sentencia T-483/12, M.P. Gabriel Eduardo Mendoza Martelo.

10. La literatura sobre el tema es escaza. Los manuales de procedimiento penal colombiano "tradicionales", no se ocupan de esta fase de ejecución de la pena, Cfr. Bernal y Montealegre (1985, 1990, 2002 y 2004) y Martínez Rave (1994, 1997, 2002 y 2006), con excepción del texto de Espitia (2010, p. 461-471), donde sumariamente se expone este tópico, ratificando así lo expresado por Foucault en el sentido que "El castigo tenderá, pues, a convertirse en la parte más oculta del proceso penal" FOUCAULT, Michel. Vigilar y castigar. Nacimiento de la prisión, México: Siglo XXI Editores, 1983, p. 17. En sentido similar al desarrollado por Espitia sobre la ejecución de la pena, se encuentra a Urazán (2002). En los textos de Fierro-Mendez (2012, p. 1722) y Urrutia y Cuesta $(2008, p$. 1145) se desarrolla el tema sin embargo, estos libros no están catalogados dentro de ese ámbito "tradicional". Mauricio Rubio (1996) al hablar de la cronología del proceso judicial refiere que "la última etapa la constituye la intervención del aparato judicial para solucionar mediante sentencia el litigio". ¿Qué pasa entonces con la ejecución de la pena? ¿No hace parte del proceso penal? Roxin (2000) dentro del capítulo 11 hace algunos comentarios sobre la ejecución de la pena pero no desarrolla el tema. Ferrajoli (1997, pp. 727-728) anota algunas referencias sobre las penas sustitutivas y López Barja, a pesar de su fervoroso discurso sobre la importancia del Juez "de vigilancia penitenciaria" (2012, p.p. 2323-2324) se limita a analizar los recursos contra las decisiones de estos jueces. Por otra parte, Jiménez (1949, p.433) consagra un capítulo sobre la ejecución de la pena que no
En virtud de este suceso, el presente artículo de reflexión, pretende responder a la siguiente pregunta de investigación: ¿cuáles fueron las modificaciones introducidas por la Ley 1709 de 2014 a los subrogados penales? Paralelamente, a raíz de la pregunta planteada y el trabajo de campo realizado, este texto analiza las consecuencias, positivas o negativas de dichas modificaciones. En virtud de lo anterior, se ofrece al lector una exposición in extenso de los subrogados penales, junto con las modificaciones legislativas más recientes, para demostrar que la respuesta frente a la crisis carcelaria es positiva en varios aspectos, aunque quedan latentes ciertos vacíos o cuestionamientos legislativos.

En cuanto a la metodología para realizar la investigación se recurrió a: (i) investigación doctrinaria; (ii) trabajo de campo en juzgados de ejecución de penas y medidas de seguridad de Bogotá y (iii) análisis normativo y jurisprudencial.

Una vez agotada la anterior descripción, procedemos a exponer la estructura que sigue el presente texto: 1.) Contexto. En este acápite se aborda la crisis del sistema carcelario en Colombia a la luz de unas circunstancias económicas, políticas y sociales sobre las cuales recae la existencia de dicha problemática. 2.) Sobre las multas y los delitos excluidos para acceder a subrogados. Estos aspectos tienen aplicación transversal a todos los subrogados y merecen ser estudiados, en la medida que la multa insoluta, con anterioridad a la reforma, imposibilitaba en gran medida la concesión de subrogados. En el mismo sentido, con independencia del cumplimiento de los requisitos exigidos para acceder aquellos, algunos

hace relación a los mecanismos sustitutivos de la pena. En el ámbito sustantivo nacional, la situación es diferente y aunque no se ocupan de la fase de ejecución -propia del procedimiento penal- hacen relación a la libertad condicional en su calidad de subrogado penal. Cfr. en este sentido Arboleda y Ruiz (202, p. 323), Reyes (1974, p. 364) y Velázquez (2007, p. 614 y 2009, p. 1167). Este último dentro del capítulo decimoctavo, aparte $C$, habla de los mecanismos sustitutivos de la pena de prisión y desarrolla la libertad condicional. Por la doctrina foránea baste citar a Zaffaroni (1983) que en el aparte IV dentro del capítulo XL "La libertad condicional como última etapa de la ejecución de la pena privativa de la libertad" desarrolla el tema. No obstante lo anterior, los sistemas de vigilancia electrónica como sustitutivos de la pena de prisión, es un tema poco desarrollado en los textos penales, encontrando sólo en Urrutia y Cuesta (2009, p. 111112) una precaria descripción exegética (que algunos calificarían como "auténtica") sobre el tema.

11. Por medio de la cual se reforman algunos artículos de la Ley 65 de 1993, de la Ley 599 de 2000, de la Ley 55 de 1985 y se dictan otras disposiciones. 
delitos se encuentran excluidos expresamente, imposibilitando dicho beneficio.

Luego de estos capítulos iniciales se estudiarán cada uno de los subrogados penales, consagrados en la legislación colombiana: 3.) Libertad condicional, 4.) Suspensión condicional de la ejecución de la pena y 5.) Prisión domiciliaria. En el acápite 6.), haremos algunas reflexiones relacionadas con la aplicación de la ley en el tiempo, el principio de favorabilidad penal y la lex tertia, así como la derogatoria tácita de algunas normas jurídicas. Esto en virtud de la coyuntura de interpretación judicial que ha originado la entrada en vigencia de la Ley 1709. El texto termina con algunas conclusiones y la recapitulación de algunos puntos importantes.

\section{CONTEXTO. CRISIS DEL SISTEMA CARCELARIO COLOMBIANO}

Uno de los deberes principales del Estado Social de Derecho es mantener un equilibrio entre la forma en que el Estado ejerce poder sobre los ciudadanos, para garantizarle a la sociedad un mínimo de seguridad pública y respetar los derechos de dichos ciudadanos. En el caso en concreto estamos frente al poder que tiene el Estado para coartar a una persona de ejercer su derecho a la libertad, al imponerle el castigo de prisión por haber infringido una norma $^{12}$. Insistimos, la ostentación de dicho poder por parte del Estado no significa que sean de menor envergadura en la agenda política y legislativa del mismo, problemáticas derivadas de este hecho, como lo es el hacinamiento carcelario y la grave crisis de este sistema.

En entrevista realizada al profesor Libardo Ariza (Universidad de los Andes), sobre la situación carcelaria en Colombia, manifiesta que: "El hacinamiento ha alcanzado su máximo histórico, llegando al 48\%; la tasa de encarcelamiento en Colombia ha aumentado de modo vertiginoso, pasando de 80 internos por

12. WASHINGTON OFFICE ON LATIN AMERICA, Sistemas Sobrecargados: Leyes de drogas y cárceles en América Latina, Ámsterdam/Washington: Editores WOLA y TNI, 2010, p. 5 cada 100.000 habitantes en 1993 a 231 reclusos por cada 100.000 en la actualidad, siempre en condiciones infrahumanas"13.

Así, desde el año 2007 se viene presentando un crecimiento exponencial en la tasa de hacinamiento carcelario en nuestro país. En el año mencionado se evidenció un nivel de hacinamiento del $17,2 \%$, aumentando sustancialmente a $25,5 \%$ en el 2008 . Para julio del 2009 la tasa de hacinamiento rondaba el $35,8 \%$ y para marzo de 2010 ascendía al $41,7 \%^{14}$. Tal es el problema por el que atraviesa Colombia respecto de ésta problemática que tanto instituciones internacionales como Gobiernos extranjeros han intervenido ${ }^{15}$.

No obstante lo anterior, la problemática del hacinamiento carcelario no se hace menos evidente ni resulta menos preocupante en el resto de países latinoamericanos. El incremento de la población carcelaria no es correlativo con el presupuesto económico que se ha destinado para ésta. Lo anterior genera una serie de condiciones deplorables que "afectan el espacio vital, la alimentación, la salud y la seguridad de los

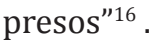

Continuando con el caso específico de Colombia, ante la gravedad del problema, la Corte Constitucional en sentencia T-153 de $1998^{17}$, declara el estado de cosas inconstitucional en los establecimientos penitenciarios del país, al considerar que las condiciones de hacinamiento al interior de las cárceles imposibilitan el adecuando desarrollo del interno para lograr los fines de la resocialización de éste al conglomerado social. El Tribunal Constitucional constata,

13. "Reforma al Código Penitenciario dejaría libres a 48 mil presos". Disponible on line: http://www.elespectador. $\mathrm{com} /$ noticias/politica/articulo-413945-reforma-al-codigopenitenciario-dejaria-libres-48-mil-presos. (Página de internet consultada por última vez el 5 de agosto de 2014).

14. GRUPO DE DERECHO DE INTERÉS PÚBLICO, Situación carcelaria en Colombia. Informe sombra presentado al CHD de Naciones Unidas, Bogotá: Facultad de Derecho, Universidad de los Andes, 2010, p. 12

15. GRUPO DE DERECHO DE INTERÉS PÚBLICO, Situación carcelaria, cit. nota $n^{\circ} 18$, p. 42

16. WASHINGTON OFFICE ON LATIN AMERICA, Sistemas sobrecargados, cit. nota $n^{\circ} 16, p .8$.

17. M.P. Eduardo Cifuentes Muñoz 
(...) una flagrante violación de un abanico de derechos fundamentales de los internos en los centros penitenciarios colombianos, tales como la dignidad, la vida e integridad personal, los derechos a la familia, a la salud, al trabajo y a la presunción de inocencia, etc. ${ }^{18}$.

De la mano de datos numéricos, se puede rescatar que en aras de dar cumplimiento a uno de los pronunciamientos más contundentes del Tribunal Constitucional, se identifica un incremento que se mantiene desde el año 2001 hasta el 2002. El nivel de hacinamiento para el año 2000 ascendía a 35,7\%, mientras que durante los siguientes dos años, la tasa no se elevó más del 15,9\%, para luego, en el año 2003 elevarse sustancialmente al 29,0\% ${ }^{19}$.

Vale la pena resaltar que esta situación carcelaria, además de ser violatoria de derechos, va en contravía de normas de carácter internacional como lo es el Pacto Internacional de Derechos Civiles y Políticos. No solo eso, sino que el fin del tratamiento penitenciario radica en lograr la resocialización de los sentenciados, lo cual se ve truncado por las condiciones mismas en las que habitan las personas en las cárceles. Si bien desde 1998, cuando se tomó la primera medida drástica por parte del gobierno, han transcurrido más de diez años, es lamentable no poder decir que el panorama ha cambiado para los centros penitenciarios en Colombia.

Sobre esta problemática, el trabajo de campo realizado por el Grupo de Prisiones de la Universidad de los Andes en el Establecimiento Penitenciario y Carcelario "El Buen Pastor" y en el Establecimiento Penitenciario y Carcelario "La Modelo", permitió a los estudiantes interactuar con los internos ahí retenidos, pudiendo extraer de primera mano las condiciones en las que viven día a día. Más de uno cuenta que la guardia del INPEC abusa de su posición, tratando con desprecio y grosería a los internos. Por otra parte, en una ocasión un interno de "La Modelo" contó que él dormía por las noches en un corredor a falta de celda. A las celdas, únicamente tienen acceso quienes puedan pagar un precio mínimo

18. Sentencia T-153 de 1998.

19. WASHINGTON OFFICE ON LATIN AMERICA, Sistemas sobrecargados, cit. nota $n^{\circ} 16, p .47$. por ella. De igual manera, cuentan las internas del "Buen Pastor" que la comida es desagradable y que más de una vez han salido gusanos en ella.

Uno de los objetivos principales de la Ley 1709 de 2014 es descongestionar las cárceles para atenuar la situación de hacinamiento que está sufriendo el país, por medio de la flexibilización de las medidas privativas de la libertad. Dicho en otras palabras:

(...)la crisis del sistema penitenciario, causada por la proliferación de normas que fomentan la privación de la libertad, la ausencia de una política criminal y la desarticulación de las entidades vinculadas, entre otros aspectos, motivó al Ministerio de Justicia a plantear una estrategia destinada a contrarrestarla y evitar que ella se repita ${ }^{20}$.

Los párrafos anteriores ponen de presente el contexto de la problemática a partir de la cual se desarrolló el presente trabajo de investigación. Si bien se expone un análisis de las modificaciones que introduce la Ley 1709 de 2014, no hay que dejar de lado que la misma entró en vigencia en enero de este año (2015), por lo que no es posible establecer a ciencia cierta la efectividad de la misma como respuesta a la problemática del hacinamiento carcelario. Sin embargo, el cónsul de derechos humanos de la Cárcel La Modelo Hernán Ciprian ${ }^{21}$, anticipa, que el impacto es notorio en materia de prisión domiciliaria.

\section{SOBRE LAS MULTAS Y LOS DELITOS EXCLUIDOS PARA ACCEDER A SUBROGADOS Y BENEFICIOS ADMINISTRATIVOS}

Antes de entrar a analizar cada subrogado penal individualmente, cabe mencionar que la Ley 1709 de 2014 excluye la obligación del pago de multas para acceder a la libertad, a subrogados penales y a los beneficios judiciales o administrativos. La ley establece que con acuerdo previo de los

\begin{abstract}
20. "Esta es la nueva reforma al Código Penitenciario". Disponible on line: http://www.ambitojuridico.com/ BancoConocimiento $/ \mathrm{N} /$ noti140121-06esta_es_la_reforma_al codigo_penitenciario/noti140121-06esta_es_la_reforma_al_ codigo_penitenciario.asp (Página de internet consultada por última vez el 5 de agosto de 2014).
\end{abstract}

21. Entrevista realizada el 14 de mayo de 2014 
entes territoriales, quienes no posean recursos para pagar la multa, lo puedan hacer por medio de servicio no remunerado a la comunidad. En efecto, anteriormente se negaba la concesión de subrogados penales en una gran cantidad de casos, pues la mayoría de la población carcelaria no cuenta con los recursos para pagar la multa.

Al respecto, nuevamente sirve de insumo el trabajo de campo que ha venido realizando el Grupo de Prisiones de la Universidad de los Andes en el Establecimiento Penitenciario y Carcelario "El Buen Pastor", en donde se logró corroborar lo dicho anteriormente. Gran parte de las internas que se encuentran allí recluidas, han sido condenadas por delitos de narcotráfico; delitos que terminan cometiendo por meras necesidades económicas. Como se evidenció en varias entrevistas con las internas, en la mayoría de casos, la concesión de alguno de los subrogados era negada porque no poseían la capacidad económica para realizar el pago de la multa.

Así pues, la eliminación de este requisito puede repercutir de la siguiente manera: por un lado, al permitir pagar la multa por medio de servicio a la comunidad las personas pueden desarrollar, eventualmente, sentido de la pertenencia así como disciplina y esfuerzo, lo cual puede tener un impacto positivo en las vidas de las personas. Por otro lado, los niveles de hacinamiento en las cárceles decrecerán, en la medida en que el pago de la multa no es un impedimento para purgar la pena en lugar distinto al establecimiento penitenciario, incrementando la posibilidad de que los subrogados y beneficios sean concedidos.

Por otra parte, la reforma hace una modificación importante al artículo 68 A del Código Penal. El mencionado artículo contiene los delitos que serán excluidos para efectos de acceder a beneficios judiciales o administrativos y a subrogados penales. Si bien la reforma reitera que la persona no podrá acceder a los mismos si tiene antecedentes, es decir, que ha sido condenada por delito doloso en los cinco años anteriores, la lista de delitos se torna mucho más extensa. Se conservan los delitos contra la Administración Pública, soborno transnacional y estafa, y abuso de confianza que recaigan sobre los bienes del Estado, entre otros, pero se adicionan varios más.

Según estadísticas del INPEC ${ }^{22}$, para marzo del 2014, tanto en hombres como mujeres, el delito más cometido es el hurto. Para este mes hay un total de 30,137 personas que cometieron dicho delito. Dentro de los delitos que agrega la reforma al artículo $68 \mathrm{~A}$, encontramos el hurto calificado, por lo que se puede afirmar que esta excepción pone una gran limitante al momento de acceder a subrogados penales y beneficios administrativos.

Continuando con las mencionadas estadísticas del mes de marzo, el segundo delito más cometido, 29.447 personas, es el homicidio, luego la fabricación, tráfico y porte de armas de fuego, cometido por 25.900 personas y, no muy distante en términos numéricos, el tráfico, fabricación o porte de estupefacientes cometido por 24.535 personas. Puesto que los delitos relacionados con el tráfico de estupefacientes y otras infracciones fueron agregados al artículo 68 A del Código Penal y los datos arrojados ponen de presente que dichos delitos son de los más cometidos, es posible afirmar que la nueva ley impone una nueva traba en la práctica para la concesión de subrogados y beneficios ${ }^{23}$.

22. RIAÑO VARGAS, Juan Manuel. Informe Estadístico Marzo 2014. Ministerio de Justicia y Derecho. p. 17.

23. ARTíCULO 32. Modifícase el artículo 68A de la Ley 599 de 2000 el cual quedará así:

Artículo 68A. Exclusión de los beneficios y subrogados penales. No se concederán; la suspensión condicional de la ejecución de la pena; la prisión domiciliaria como sustitutiva de la prisión; ni habrá lugar a ningún otro beneficio, judicial o administrativo, salvo los beneficios por colaboración regulados por la ley, siempre que esta sea efectiva, cuando la persona haya sido condenada por delito doloso dentro de los cinco (5) años anteriores. Tampoco quienes hayan sido condenados por delitos dolosos contra la Administración Pública; delitos contra las personas y bienes protegidos por el Derecho Internacional Humanitario; delitos contra la libertad, integridad y formación sexual; estafa y abuso de confianza que recaigan sobre los bienes del Estado; captación masiva y habitual de dineros; utilización indebida de información privilegiada concierto para delinquir agravado; lavado de activos; soborno transnacional; violencia intrafamiliar; hurto calificado; extorsión, lesiones personales con deformidad causadas con elemento corrosivo; violación ilícita de comunicaciones; violación ilícita de comunicaciones o correspondencia de carácter oficial; trata de personas; apología al genocidio; lesiones personales por pérdida anatómica o funcional de un órgano o miembro; desplazamiento forzado; tráfico de migrantes; testaferrato; enriquecimiento ilícito de particulares; apoderamiento de hidrocarburos, sus derivados, biocombustibles o mezclas que los contengan; receptación instigación a delinquir; empleo o lanzamiento de sustancias $u$ objetos peligrosos; fabricación, importación, tráfico, posesión o uso de armas químicas, biológicas y nucleares; delitos relacionados con el tráfico de estupefacientes y otras infracciones; espionaje; rebelión y desplazamiento forzado; usurpación de inmuebles, falsificación de moneda nacional o extranjera; exportación o importación ficticia; evasión fiscal; negativa de reintegro; contrabando agravado; contrabando de hidrocarburos y sus derivados; ayuda e instigación al empleo, producción y transferencia de minas antipersonal. Lo dispuesto en el presente artículo no se aplicará respecto de la sustitución de la detención preventiva y de la sustitución de la ejecución de la pena en los eventos contemplados en los numerales 2 3, 4 y 5 del artículo 314 de la Ley 906 de 2004.

PARÁGRAFO 1o. Lo dispuesto en el presente artículo no se 
Con base en lo expuesto previamente, si bien la exclusión del pago de la multa puede, para efectos prácticos, tener un impacto positivo al eliminar una evidente traba para el acceso a los subrogados penales y beneficios, la modificación al artículo 68 A del Código Penal, puede acarrear inclusive más restricciones. Esto, no solo por incluir una lista mucho más extensa de delitos excluidos, sino porque en la práctica se evidencia que los delitos que más se siguen cometiendo hacen parte de esta lista.

Aunque visto desde esta perspectiva (donde un espectro más amplio de personas se les trunca la posibilidad de acceder a algún subrogado o beneficio), es posible otorgarle un tinte negativo a la modificación introducida a éste artículo, es necesario poner de presente que el mismo no aplica ni para el subrogado de la libertad condicional ni para la novedosa modalidad de prisión domiciliaria por el cumplimiento de la mitad de la condena en pena intramural, que tiene unas exclusiones diferentes.

Teniendo en cuenta que el mismo artículo excluye de su rango de aplicación estas medidas, la modificación introducida suscita otro tipo de cuestionamientos, pues en determinados casos y teniendo en cuenta el contexto, el cumplimiento de la sanción de la conducta punible ${ }^{24}$ sí amerita un tratamiento menos laxo. Tal es el caso de los funcionarios públicos, el cual será explicado en detalle más adelante, quienes cometen delitos contra la Administración Pública y pueden acceder a la concesión éstos subrogados en razón de la no aplicación del artículo 68 A.

\section{LIBERTAD CONDICIONAL}

Previo a analizar el subrogado penal de la libertad condicional, a la luz de la Ley 1709 de 2014, es necesario definirlo y comprender la figura desde un punto de vista doctrinal. Según Alderete

aplicará a la libertad condicional contemplada en el artículo 64 de este Código, ni tampoco para lo dispuesto en el artículo $38 \mathrm{G}$ del presente Código.

PARÁGRAFO 2o. Lo dispuesto en el primer inciso del presente artículo no se aplicará respecto de la suspensión de la ejecución de la pena, cuando los antecedentes personales, sociales y familiares sean indicativos de que no existe la posibilidad de la ejecución de la pena.

24. "Comportamiento humano que lesiona o pone en peligro un bien jurídicamente protegido". ARBOLEDA, Mario y RUIZ, José, Manual de Derecho Penal. Partes General y Especia, Bogotá: Editorial Leyer, 2014, p. 145. "la libertad condicional es un instituto a través del cual la autoridad judicial, previa solicitud del interesado y luego de verificar el cumplimiento de determinadas exigencias legales, dispone la suspensión de la ejecución de la pena privativa de la libertad, a cambio de que el condenado acepte someterse a ciertas condiciones durante un período de prueba"25. En otras palabras, el Estado autoriza al condenado para egresar del establecimiento penitenciario previo a cumplir la totalidad de la pena intramuros, siempre que haya cumplido un tiempo determinado y su conducta allí haya sido apropiada, pero quedando sujeto a vigilancia durante un tiempo.

Si bien los orígenes más conocidos de la libertad condicional datan de 1791 en Inglaterra ${ }^{26}$ , éste subrogado está estrechamente ligado con los regímenes penitenciarios progresivos. Comúnmente la doctrina ha esbozado tres fundamentos generales atribuibles a la aparición de la institución en comento. En una primera instancia, la aparición de la libertad condicional refleja la necesidad de mantener un orden al interior de los establecimientos penitenciarios a partir de una conducta adecuada por parte de los condenados. El observar una buena conducta al interior de la cárcel y acatar las normas disciplinarias de las mismas, supone una motivación para el condenado con el fin de poder acortar su estadía en el establecimiento ${ }^{27}$.

Por otro lado, la libertad condicional también cumple con una función de rehabilitación, pues al liberar anticipadamente al condenado, tanto él mismo como la sociedad se ven beneficiados. Lo anterior quiere decir que el condenado ha logrado salir anticipadamente del encierro porque el objetivo de la pena, en efecto logró ser cumplido al mostrar una paulatina recuperación y así poderle aportar a la sociedad de manera útil ${ }^{28}$. De la mano de lo anterior, es posible considerar a la libertad condicional como una de aquellas instituciones liberadoras, cuyo objetivo es claramente mejorar la situación de los condenados. En estas, "se tiene más

25. ALDERETE, Rubén. La Libertad Condicional en el Código Penal Argentino. Buenos Aires: LexisNexis, 2007, p. 2.

26. ALDERETE, La libertad condicional, cit. nota $n \stackrel{o}{29}$, p. 2.

27. ALDERETE, La libertad condicional, cit. nota $n \stackrel{\circ}{29}$, p. 19

28. ALDERETE, La libertad condicional, cit. nota $n \stackrel{\circ}{29}$, pp. 20 y 21 . 
en cuenta al hombre que delinque que al hecho que cometió, considerando la necesidad de reformar, de readaptar, de reeducar a los delincuentes como medio de combatir la criminalidad ${ }^{29 "}$.

Según la visión del profesor Reyes Echandía (Q.E.P.D.), la libertad condicional comprende dos componentes fundamentales. En primer lugar, un componente moral donde el condenado se ve retribuido por haber evidenciado capacidad de readaptación. En segundo lugar, un componente social que estimula a los demás sentenciados a seguir el mismo camino de su compañero a quien premiaron ${ }^{30}$.

Finalmente, la libertad condicional es considerada como una herramienta idónea para atacar el hacinamiento en las cárceles, el cual es un problema que le hace frente a todo el mundo. Así, la libertad condicional disminuye considerablemente la pena que el condenado tiene que cumplir intramuros para acceder anticipadamente a la libertad ${ }^{31}$.

Ahora bien, el artículo 30 de la Ley 1709 del 2014, modifica el artículo 64 de la Ley 599 del 2000 el cual regula lo atinente a la libertad condicional. Para efectos de la concesión de este subrogado se hace referencia a un requisito objetivo en el cual se deben cumplir las $3 / 5$ partes de la pena por parte del sentenciado. Antes de la entrada en vigencia de la ley del 2014, había una diferencia en el quantum del requisito objetivo con base en el sistema de enjuiciamiento penal por el que se rigiera el proceso. Así, el legislador estableció que para los procesos regidos por la Ley 906 de 2004 (sistema con tendencia acusatorio), el condenado debía cumplir las $2 / 3$ partes de la pena, mientras que para los procesos regidos por la Ley 600 de 2000 (sistema mixto con tendencia inquisitiva), correspondía a las $3 / 5$ partes de la pena. Bajo los lineamientos de la Ley 1709 quedó unificado dicho requisito.

Paralelamente, el mismo artículo hace especial mención a que se demuestre el arraigo social y familiar. De otro lado, si bien en la redacción

29. DAIEN, Samuel, Régimen jurídico y social de la libertad condicional, Buenos Aires: Editorial Bibliográfica Argentina, 1947, p. 115.

30. REYES ECHANDÍA, Alfonso, Derecho Penal. Parte General, Bogotá: Editorial Temis, 1994, p. 297.

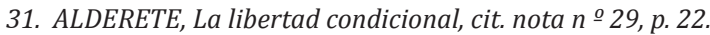

se modifica ligeramente, el requisito subjetivo que implica concepto favorable por parte del establecimiento penitenciario, continúa siendo necesario, en virtud del numeral 2 .

No obstante, cabe resaltar que la concesión de dicho subrogado está sujeta "a la reparación a la víctima o al aseguramiento del pago de la indemnización mediante garantía personal, real, bancaria o acuerdo de pago, salvo que se demuestre insolvencia del condenado ${ }^{32}$. En este punto, vale la pena hacer mención a uno de los grandes beneficios que trae la Ley 1709 de 2014: excluye la obligación del pago de multas ${ }^{33}$ para acceder a la libertad, a subrogados penales y a los beneficios administrativos (supra 2). Esta postura es una respuesta que se asimila a la tesis sobre la discriminación por situaciones de pobreza respecto a la sustitución de la prisión por multa, sostenida por la Suprema Corte de los Estados Unidos en los casos Tate Vs. Short, 401 U.S. 395 (1971) y Williams Vs. Illinois, 399, U.S. 235 (1970) ${ }^{34}$.

Siguiendo con este análisis comparado, en el artículo 13 Código Penal argentino se consagra la misma exigencia; sin embargo, su jurisprudencia es más restrictiva que la nuestra: en caso de que el condenado no tenga recursos, la multa se convierte en días de prisión, acorde con lo establecido en el artículo 21 del mismo Código ${ }^{35}$.

Así pues, antes de la entrada en vigencia de la citada ley, la concesión de la libertad condicional estaba supeditada al pago de la multa y por esto, como lo afirman la Juez $1^{\text {a }}$ y 7 de Ejecución de Penas y Medidas de Seguridad de Bogotá ${ }^{36}$, se negaban una gran cantidad de ellas. En el presente, con la exclusión de este requisito, la concesión de este subrogado ha aumentado sustancialmente; sin embargo, no se debe dejar de lado que el pago de los perjuicios a las víctimas se sigue exigiendo.

\section{Artículo 30 Ley 1709 de 2014}

33. Cfr. Gacetas del Congreso de Colombia 298 (20-05-13), 668 (02-09-13), 941 (20-11-13) en la exposición relacionada con el "régimen de libertades".

34. En contra de esta posición ver Posner, Richard, El análisis económico del derecho, México: Fondo de Cultura Económica, 2002, p. 218.

35. ALDERETE, La libertad condicional, cit. nota $n^{\circ} 29$, p. 148

36. Entrevistas realizadas el 24 de abril y 29 de mayo de 2014, respectivamente. 
Lo anterior implica que los juzgados continúan oficiando a las respectivas entidades con el fin de verificar la situación económica de la persona y, en caso de demostrar insolvencia, aunque se conceda el subrogado en cuestión, no quedan exonerados del pago de perjuicios. El pago de estos no se hace exigible en el proceso penal, pero sí es exigible dentro de un proceso civil.

La misma norma jurídica, supedita la concesión del subrogado en cuestión a valoración previa de la conducta punible. En este punto entran en colación dos elementos: haber dejado vigente "la valoración de la conducta punible" versus haber eliminado el término "gravedad" para realizar la valoración de la misma. De lo anterior surge el interrogante de si efectivamente la erradicación del término "gravedad" tiene un efecto significativo para la concesión del subrogado o si, por el contrario, en el simple hecho de la valoración de la conducta queda sujeta de una u otra forma la gravedad.

Cuando un operador jurídico se ve en el deber de juzgar la conducta de un comportamiento, la valoración se debe hacer a partir de la sociedad, según la teoría del concepto social (una de las varias teorías existentes sobre la conducta). Lo anterior implica que dicho comportamiento es una conducta humana que lesiona bienes jurídicos salvaguardados por el derecho penal o, dicho de forma distinta, un comportamiento socialmente relevante, en la medida que su actuar implica una afectación con el mundo exterior ${ }^{37}$. Así, de la mano de la teoría que se acaba de exponer, la sociedad en general tiende a asociar algunas conductas como "más gravosas" que otras, lo cual permite concluir que cuando los operadores jurídicos realizan una valoración sobre alguna de estas conductas punibles así consideradas, no podrá ser del todo objetivo y eliminar de la valoración, "la gravedad". Con base en esto vale la pena preguntarnos ¿Resulta significativa la modificación legislativa realizada por el legislador al eliminar el término "gravedad", dejando vigente el análisis previo de la conducta punible? La respuesta negativa a este interrogante está sustentada en la visión de los directamente afectados y el criterio de los operadores jurídicos que confirman su dicho.

37. Entrevistas realizadas el 24 de abril (Juez 1ạ de Ejecución de Penas y Medidas de Seguridad de Bogotá) y 29 de mayo de 2014 (Juez 18 de Ejecución de Penas y Medidas de Seguridad de Bogotá).
Así y recurriendo, nuevamente, al trabajo de campo realizado por el Grupo de Prisiones de la Universidad de los Andes en el Establecimiento Penitenciario y Carcelario "La Modelo" de la ciudad de Bogotá, hemos logrado constatar, con base en las manifestaciones de los reclusos, que los Juzgados de Ejecución de Penas y Medidas de Seguridad, continúan negando la libertad condicional con sustento en el análisis de la conducta punible y la argumentación referente a su impacto en la sociedad y la víctima, así como la necesidad del tratamiento penitenciario, con independencia del concepto favorable emitido por el centro de reclusión.

Congruente con lo anterior, se puede constatar que los Juzgados continúan negando la libertad condicional, por los motivos arriba anotados, algunos cuidándose de no utilizar el término "gravedad" al valorar la conducta punible y mutando su argumentación hacia la "modalidad" de como acaeció el delito, mientras que otros continúan manejando el formato vigente antes de la reforma, cambiando únicamente la cita correspondiente a la normatividad aplicable ${ }^{38}$.

En este sentido, el pasado 7 de marzo de 2014, se entrevistó a un funcionario judicial, indagando sobre la modificación introducida por la ley 1709 y la metodología adoptada por los Juzgados de Ejecución de Penas y Medidas de Seguridad, quien al respecto, nos manifestó:

(...) el tema se está manejando igual que antes, con aplicación de la sentencia C-194 de 2005. Es más, se considera que como se eliminó el término "gravedad", la valoración puede ser más amplia y abarcar, por ejemplo, la modalidad de la conducta, pero siempre con sujeción a lo considerado por el sentenciador ${ }^{39}$.

38. Por ejemplo, en providencia del 11 de febrero de 2014, el Juzgado 5 o de Ejecución de Penas y Medidas de Seguridad de Bogotá (Proceso 24949) negó la libertad condicional, con base en la siguiente argumentación: "Si bien es cierto ya ha cumplido con las tres quintas partes de la pena, no se puede desconocer la gravedad de la conducta punible. (...) Frente a este requisito es necesario entrar a analizar la gravedad de la conducta, como fue su comportamiento cuando se cometió el delito. Fuera de la sentencia se valora la gravedad de la conducta, no responsabilidad penal del condenado, no como el resultado de un nuevo proceso de valoración sino de la necesidad del tratamiento penitenciario a causa de la gravedad del comportamiento".

39. Rolando Robayo (Ex Juez $4^{\circ}$ Penal Municipal con Función de Control de Garantías de Soacha y Ex Juez $2^{\circ}$ Penal Municipal de Facatativá - con funciones tanto de garantías como de conocimiento-. Actualmente se desempeña como asistente jurídico del Juzgado 14 de Ejecución de Penas y Medidas de Seguridad de Bogotá). 
En similar sentido, otro funcionario judicial había manifestado lo siguiente:

“ (...) de todas formas se dejó la previa valoración de la conducta que nos obliga a hacer ese estudio y así pues, por libertad condicional no es mucho lo que sale (...) si no lo hacemos entonces salen a cometer peores delitos y dicen que somos los responsables de eso" ${ }^{40}$.

La argumentación esgrimida por los Juzgados de Ejecución de Penas y Medidas de Seguridad resulta incoherente con el espíritu de la ley 1709 que propende por reivindicar el derecho a la libertad, liberando cupos en las cárceles colombianas con miras a restaurar la dignidad humana de los presos $[5]^{41}$. Igualmente, recurriendo a criterios hermenéuticos de interpretación sistemática, se puede observar, cómo en materia de suspensión condicional de la pena [29] se eliminó el requisito subjetivo que incluso exigía, una valoración de la modalidad y "gravedad" de la conducta punible ${ }^{42}$. También se excluyó la libertad condicional de la prohibición contenida en el artículo 68 A del Código Penal, como operaba con anterioridad

40. Entrevista realizada el 6 de marzo de 2014. Se hace reserva del nombre por expresa solicitud del entrevistado.

41. Los números entre llaves, contenidos en este párrafo, corresponden al articulado original de la ley 1709 de 2014.

42. El numeral 2ำ del artículo 63 del Código Penal exigía un requisito subjetivo del siguiente tenor: "Que los antecedentes personales, sociales y familiares del sentenciado, así como la modalidad y gravedad de la conducta punible sean indicativos de que no existe necesidad de ejecución de la pena" (Resaltado fuera del texto).

43. Establecía el artículo 68 A del Código Penal que: "No se concederán los subrogados penales o mecanismos sustitutivos de la pena privativa de libertad de suspensión condicional de la ejecución de la pena o libertad condicional" (Resaltado fuera del texto). a la reforma ${ }^{43}$. Con base en esto nos aventuramos a afirmar que el legislador también quería flexibilizar la concesión de la libertad condicional.

En el derecho comparado encontramos ejemplos como la ley jenna (promulgada en el Estado de New York - 1998) que establecía un requisito objetivo equivalente al $85 \%$ de la pena para los autores, quienes, por primera vez, cometían crímenes violentos, sometiéndolos a una estrecha vigilancia por el período de la libertad condicional. Incluso en estos casos los sentenciados tienen la posibilidad de acceder a este subrogado ${ }^{44}$.

Todas estas razones llevan a pensar que el obstáculo inicial que consagra el artículo 64 del Código Penal y la aplicación que le han venido otorgando los Juzgados de Ejecución de Penas y Medidas de Seguridad, no tienen cabida teleológicamente, ya que lo importante respecto a este subrogado, insistimos, es el comportamiento intramuros y no los aspectos antecedentes que determinaron su reclusión y le significaron una pena, acorde con los criterios de dosificación punitiva. Superado este escenario en sede de conocimiento, el Juzgado de Ejecución de Penas y Medidas de Seguridad debe velar, ya no por el comportamiento que originó la consecuencia jurídica de la prisión, reiterando que lo trascendental en materia de libertad condicional, no es la conducta punible sino la efectivización de los fines de la pena ${ }^{45}$.

Finalmente y acudiendo al trabajo de campo en la Cárcel La Modelo, se ofrecen las cifras de los internos que en ese establecimiento, accedieron a este subrogado penal, durante el año 2014:

Gráfica 1. Libertad condicional E. C. Bogotá 2014

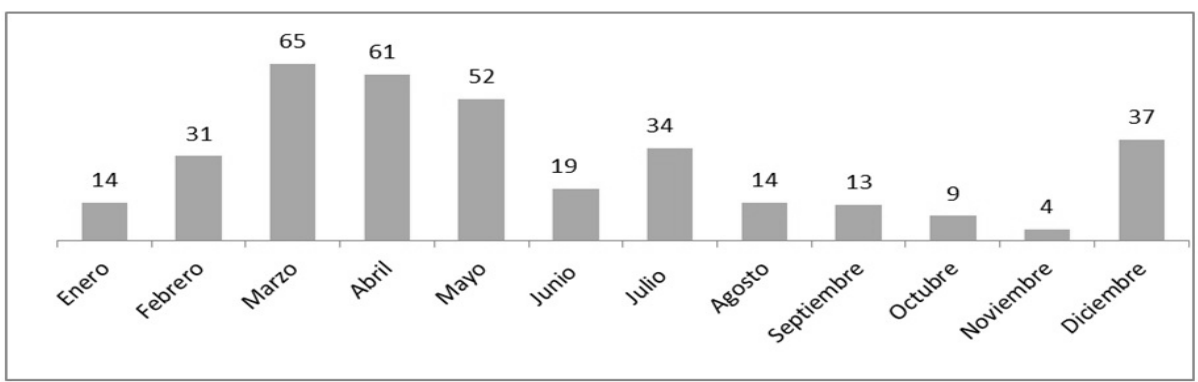

Fuente: Jurídica E.C. Bogotá (Informe Ley 1709 de 2014) 
De la anterior gráfica se desprende que en el año inmediatamente anterior, 353 internos resultaron beneficiados con la libertad condicional, siendo marzo el mes donde los Jueces decretaron más libertades de este tipo $(18,4 \%)$, mientras que en el mes noviembre, solo accedieron 4 internos, a este subrogado $(1,1 \%)$.

\section{SUSPENSIÓN CONDICIONAL DE LA EJECUCIÓN DE LA PENA}

En primer lugar, resulta pertinente para efectos de cumplir los objetivos propuestos por este documento, estudiar los antecedentes doctrinarios de la figura de la suspensión condicional de la pena y lo que se entiende por esta. Así pues, la suspensión condicional de la ejecución de la pena es comúnmente conocida como condena de ejecución condicional. Se entiende por ésta, la acción del operador jurídico que le permite poner en suspenso el cumplimiento de la pena impuesta a un individuo, quien cometió un delito leve pero que adicionalmente "las condiciones personales del mismo autorizan a presumir que la efectividad de la pena carece de objeto práctico"46. Asimismo, a través de este medio, al igual el resto de subrogados penales, es posible dar cumplimiento a la prevención especial, como uno de los fines de la pena.

Dicho en otras palabras: prevalece la libertad, aunque sujeta a obligaciones previstas por el legislador. Previo cumplimiento de las mismas, el condenado no tiene que internarse en un establecimiento penitenciario. Si bien el

44. GARLAND, David, La cultura de las sociedades con altas tasas de criminalidad. Algunas precondiciones de las políticas de seguridad ciudadana, En: Crimen y castigo en la modernidad tardía. Estudio preliminar Manuel A. Iturralde, Bogotá: Siglo del Hombre, Universidad de los Andes y Pontificia Universidad Javeriana, 2007, p. 218

45. Cfr. Artículo $4^{\circ}$ del Código Penal.

46.FONTÁN, Carlos, Tratado de derecho penal. Tomo III, Buenos Aires: Abeledo Perrot S.A, 1995, p. 409.

47. RUIZ, Equitipicidad, cit. nota $n^{\circ}$ 2, p. 243.

48.FIERRO, Heliodoro, La libertad provisional y condicional en el derecho procesal penal, Bogotá: Editorial Leyer, 1998, p. 225.

49. RUIZ, Equitipicidad, cit. nota $n^{\circ}$ 2, p. 243.

50. RUIZ, Equitipicidad, cit. nota $n^{\circ}$ 2, p. 243. condenado bajo esta medida no tiene que purgar su pena en la cárcel, lo anterior no implica que la pena deje de existir. Por esta razón, si el sentenciado no cumple las obligaciones a las que está sujeto durante el periodo de prueba, se revoca instantáneamente el beneficio y cumple el tiempo que le reste intramuros ${ }^{47}$.

Es importante poner de presente la definición que le otorga a ésta medida Fierro-Méndez, quien considera que este subrogado es: "la suspensión del inicio de la pena privativa de la libertad contenida en una sentencia de condena ${ }^{48}$.

Se ha discutido de antaño en la comunidad constitucional si en efecto la condena subsiste o si por el contrario se extingue definitivamente. Aquellos que sostienen la primera posición consideran por un lado lo siguiente: dado que los condenados están bajo el otorgamiento de un beneficio, la pena necesariamente debe subsistir con el fin de contabilizar el tiempo que han gozado del mismo como parte del cumplimiento mismo de la pena. De igual manera, consideran que por el simple hecho de estar sujetos al cumplimiento de unas obligaciones durante el periodo de prueba, cuya inobservancia acarrea el fin de la ejecución del beneficio, no puede significar que la condena se extingue. Adicionalmente, arguyen estos mismos, aunque se produzca un efectivo cumplimiento de la obligaciones, en los antecedentes penales del individuo constará la comisión del delito cometido y figurará en calidad de condenado ${ }^{49}$. Otra posición es sostenida por el profesor Luis Carlos Pérez (Q.E.P.D.), citado por Ruiz Rengifo, quien dice que "la condena se extingue definitivamente pero la comisión del hecho no se borra como tampoco desaparece el juicio seguido al agente" ${ }^{\prime 2}$.

En todo caso, es posible afirmar que el análisis que debe realizar el operador jurídico con el fin de determinar si concede o no el subrogado en cuestión, se debe dar sobre el entendido de que el derecho penal opera como ultima ratio.

Se le pueden atribuir cinco características particulares que configuran la columna vertebral de este subrogado penal. En primer lugar, junto con la sentencia, es el único momento en que se puede otorgar, salvo que haya tránsito de legislación, como ocurre con la entrada en vigencia de la Ley 1709 , que modificó el requisito objetivo, habilitando un nuevo estudio de este 
subrogado, por parte del Juez de Ejecución de Penas y Medidas de Seguridad. En segundo lugar, procede de oficio o a petición de parte. Tercero, suspende un lapso del cumplimiento de la pena. Adicionalmente, su concesión está sujeta a la voluntad del legislador y finalmente, lo otorga el juez de conocimiento ${ }^{51}$, por regla general.

Uno de los fundamentos principales que entrañan las instituciones sustitutivas de la pena de libertad es que la estadía en establecimientos de reclusión cuando se trata de cortos periodos de tiempo, no son eficaces ${ }^{52}$. Es por esto que debe quedar claro que el fin que persigue esta institución es precisamente el de evitar o impedir las penas en establecimientos penitenciarios, donde además de no cumplir con el fin resocializador de la pena ${ }^{53}$, "son perniciosas y corruptoras por el contacto con los otros reos incorregibles y avezados en el delito ${ }^{54 "}$.

Sobre los antecedentes de esta institución no ha sido posible trazar un origen indiscutible. Algunos atribuyen sus orígenes a sucesos relacionados con delincuentes menores de dieciséis años, en el Estado de Massachusetts, en Estados Unidos. En el caso de éstos, se les suspendió el pronunciamiento de la sentencia pero quedando sometidos a un período de prueba de dos años. Durante este período, quedaban sujetos a vigilancia por parte de funcionarios $\mathrm{y}$ en caso de que no volvieran a infringir la ley, se eliminaba el delito de sus antecedentes ${ }^{55}$. Sin embargo, otros consideran que esta figura tiene sus orígenes en Bélgica, introducida por medio de la Ley del 29 de abril de $1888^{56}$. Estadísticas de la época constataron que únicamente tres individuos, de cien a quienes se les aplicó la condena condicional, reincidieron ${ }^{57}$. Luego, es posible traer a colación a Francia en donde esta institución apareció en 1891 por medio de la Ley Berenguer y, en el transcurso de diez años, luego de la entrada en vigencia de la

51. FIERRO, La libertad provisional, cit. nota $n \stackrel{\circ}{\circ}$ 52, p. 225 .

52. PABÓN, Pedro, Manual de Derecho Penal. Parte General. Tomo I, Bogotá: Ediciones Doctrina y Ley, 2013, pp. 621 y 672.

53. RUIZ, Equitipicidad, cit. nota $n \stackrel{\circ}{2}$ 2, p. 246.

54. FONTÁN, Tratado, cit. nota n o 50, p. 409.

55. FONTÁN, Tratado, cit. nota $n^{\circ}$ 50, p.411.

56. RUIZ, Equitipicidad, cit. nota $n^{\circ}$ 2, p. 243.

57. FONTÁN, Tratado, cit. nota $n \stackrel{0}{0}$ 50, p. 411. citada ley, fue posible confirmar que los índices de reincidencia disminuyeron ${ }^{58}$. Dicho lo anterior, la aparición de esta institución está inspirada sobre la base de dos conceptos: los antecedentes y las penas de corta duración.

Antes de continuar, sobre el concepto de las penas de corta duración, es pertinente detenerse brevemente para hacer un comentario. Si bien corrientes doctrinales consideran que el castigo para las penas de corta duración no debe ser el establecimiento carcelario, por cuanto no cumple con el fin resocializador de la pena, en algunos contextos los delitos menores cuyas penas no son tan altas, pueden influir negativamente en la realidad de la sociedad. Ésta última posición es sostenida por el ex- alcalde de la ciudad de Nueva York Rudolph Giuliani, cuando se pronunció sobre la situación carcelaria de nuestro país. Según su criterio, tratándose de un país donde la criminalidad es muy alta, la respuesta no es dejar por fuera de las cárceles a aquellos delincuentes que comenten delitos menores ya que esto fomenta la comisión de delitos, sino tener más cantidad de establecimientos carcelarios ${ }^{59}$.

Sobre el entendido de los anteriores conceptos, se ahondará en los requisitos impuestos por la ley, referentes a la concesión de este beneficio y las modificaciones que introduce la reforma.

Así, el primer inciso del artículo 29 de la Ley 1709 de 2014 que modifica el artículo 63 del Código Penal, consagra que:

"La ejecución de la pena privativa de la libertad impuesta en sentencia de primera, segunda o única instancia, se suspenderá por un período de dos (2) a cinco (5) años, de oficio o a petición del interesado, siempre que concurran los siguientes requisitos".

Bajo la redacción del legislador del 2014, se tiene claridad sobre en qué momento se puede solicitar el subrogado bajo análisis. No obstante, en el Código Penal colombiano de 1936, lo anterior no era evidente, lo cual levantó una gran polémica, al no saber a ciencia cierta si se solicitaba junto con la sentencia o luego del fallo ${ }^{60}$.

\section{FONTÁN, Tratado, cit. nota o $^{50}$, p. 411}

59. "Seguridad de Colombia es una historia de éxito". Disponible on line: http://www.eltiempo.com/archivo/documento/CMS13939736 (Página de internet consultada por última vez el 5 de agosto de 2014)

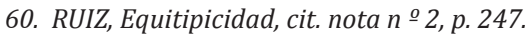


Continuando con los preceptos señalados en la ley, anteriormente el requisito objetivo para poder acceder a este subrogado, implicaba que la pena impuesta fuera inferior a tres años. Hoy, todas aquellas personas que estén efectivamente condenadas y que adicionalmente no tengan antecedentes, podrían solicitar este subrogado, sólo si la pena impuesta es igual o inferior a cuatro años.

En efecto, aumentar el requisito a 4 años permite abarcar una población un poco más amplia, apta para acceder al subrogado penal. Sin embargo, surge el interrogante de si en la práctica realmente esto acarrea un cambio significativo para efectos de la concesión del subrogado o si, por el contrario, es un mero cambio simbólico. La Juez 18 de Ejecución de Penas y Medidas de Seguridad de Bogotá61, afirma que antes de la entrada en vigencia de la nueva ley, este subrogado se concedía muy poco en dichos juzgados, pues eran pocos los casos que pasaban a ser de su conocimiento, dado que superaban así fuera por muy poco tiempo el lapso de los tres años. La misma juez afirma que para ver los resultados prácticos de la modificación frente a este requisito objetivo, es necesario esperar qué tanto, una vez el proceso se encuentre en ejecución de penas, se vuelve a solicitar este subrogado.

En segundo lugar, otro de los cambios que trae consigo la reforma es que se pueden analizar los antecedentes personales, sociales y familiares de la persona para ver si procede este "tipo de perdón que da el Estado", en caso de que estos pongan de presente que no es necesaria la ejecución de la pena. Éste análisis subjetivo solo se lleva a cabo cuando existen antecedentes penales por delito doloso. En cambio, con anterioridad a la Ley 1709 , los antecedentes personales, sociales y familiares del condenado, así como de la modalidad y gravedad de la conducta, debían indicarle al juez que no era necesario ejecutar la pena. Por esto, se concluye que el subrogado toma un tinte más objetivo, que analiza únicamente para todos los casos, la pena impuesta a la persona.

De la mano de lo anterior, el hecho de que la concesión de esta medida esté sujeta a la voluntad del legislador, pues es él quien realiza el análisis mencionado en el párrafo precedente, la Corte Constitucional puso de presente que si,

61. Entrevista realizada el 24 de abril de 2014. efectivamente, el juez considera que la conducta punible no amerita la internación, tiene la potestad de otorgarla o no. Es decir, ha dado preponderancia a la discrecionalidad del juez. En palabras de la Corte el juez puede negar la concesión del subrogado puesto que "existen razones para suponer viable la privación de la libertad cuando la personalidad del procesado aconseja en un momento dado el internamiento por las singulares características de la conducta criminosa" ${ }^{62}$.

De lo anterior resulta redundante cuestionarse, cuándo es que un individuo es apto para requerir tratamiento intramural o no. Antes este interrogante responde la Corte de esta manera:

"El estudio de la personalidad del delincuente para que realmente constituya parámetro serio para determinar la necesidad de la privación de la libertad, deber ser el resultado de un estudio que ahonde en el interior de quien ha realizado un hecho punible y no se limite a las escasas manifestaciones de la personalidad que se conocen a través del expediente"63.

Lo anterior, va de la mano de las palabras del profesor Reyes Echandía, citado por Ruiz Rengifo, quien recalca que si bien la reincidencia debe ser un criterio atendido por el juez para estimar si se otorga o no el subrogado, no puede ser el único criterio a tener en cuenta para concederlo ${ }^{64}$.

En virtud de lo expuesto previamente, es posible concluir con base en información recolectada en el trabajo de campo en el Juzgado 18 de Ejecución de Penas y Medidas de Seguridad, que previo a la entrada en vigencia de la Ley 1709 de 2014, este subrogado penal, fue el menos solicitado en este juzgado para el año 2013 y comparativamente hablando, el menos concedido. Haciendo una posible proyección del efecto de las modificaciones introducidas el presente año, dado que la pena impuesta pasa de tres a cuatro años, una mayor cantidad de la población reclusa podrá llegar a solicitar este subrogado teniendo en cuenta que en una gran cantidad de casos, por superar los tres años, no se concedía la suspensión condicional por parte de los jueces de conocimiento.

62. FIERRO, La libertad provisional, cit. nota $n^{\circ}$ 52, p. 227.

63. Ibídem.

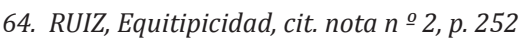




\section{PRISIÓN DOMICILIARIA}

Para realizar un análisis de cómo era la prisión domiciliaria antes y después de la entrada en vigencia de la Ley 1709 de 2014, es necesario comprender por un lado su definición junto con algunas especificaciones derivadas de ésta y, por otro, establecer que la misma es considerada como una de las medidas de carácter sustitutivo.

Más allá de la mera definición, puesto que el subrogado en consideración es la prisión domiciliaria, mal se haría en pasar de largo el fundamento y alcance del concepto de domicilio. En la doctrina comparada es posible encontrar un criterio unificado frente a la concepción el domicilio. Así, "el domicilio es el lugar donde uno se halla establecido y avecindado con su mujer, hijos y familia y la mayor parte de sus bienes muebles", según la definición de Escriche, citada por María Cristina Bucheli de Osejo ${ }^{65}$. Con el fin de mantener las distintas relaciones entre los seres humanos, que pocas veces carecen de la necesidad de desplazarse, es que surge la necesidad de crear una noción jurídica de domicilio. De esta manera se busca establecer un lugar del planeta de donde se predique la permanencia de las personas para suplantar una eventual ausencia ya que, como lo expone la doctrina francesa, todo hombre tiene necesariamente un vínculo con un lugar determinado ${ }^{66}$.

Ahora bien, del tenor de la redacción del artículo 38 del Código Penal, modificado por el artículo 22 de la Ley 1709, resulta relevante traer a colación el concepto de las penas sustitutivas, una vez entendida la definición de la prisión domiciliaria y habiendo hecho un alto para ahondar brevemente en el concepto del domicilio.

La Ley 599 del 2000 fue la encargada de introducir la noción de pena sustitutiva, en donde establece que la prisión domiciliaria será considerada como sustitutiva de la pena de prisión formalmente entendida. Este concepto tiene asidero en la "doctrina de la alternatividad penal" ${ }^{\text {" }}$. La mencionada doctrina nace a raíz de la crisis en

65. BUCHELI DE OSEJO, María, La detención domiciliaria, Bogotá: Ediciones Jurídicas Gustavo Ibáñez, 1998, p. 71.

66. Ibídem, BUCHELI DE OSEJO, nota $n^{\circ} 69$, p.70.

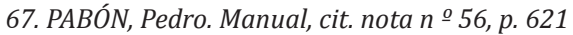

la que está sumida la prisión, no solo por la falta de relación práctica entre ella y la idea de resocializar y rehabilitar al delincuente, sino porque la cárcel misma es criminógena. Una de las explicaciones por las que la prisión como institución está en crisis es porque el objetivo de los legisladores es aislar en prisiones a los infractores de la ley, sin tratar de darle solución a la delincuencia como fenómeno. No está dentro de sus intereses

(...) volcar sobre las prisiones unos eficaces equipos humanos, entre abogados, psiquiatras, psicólogos, religiosos, asistentes sociales, criminólogos, sociólogos, para encontrar la etiología del delito y atacar sus raíces; para tratar de recuperar al hombre que hay en el delincuente; para hacerle más llevadera la vida en prisión; para hacer que se sienta una persona rescatable para su familia, para la sociedad, para el Estado, para sí mismo ${ }^{68}$.

La anterior doctrina esgrime una corriente de política penitenciaria, donde abolir por completo la pena de prisión, no es el fin buscado, pero sí limitar su aplicación y abogar por la sustitución en casos específicos ${ }^{69}$.

Aunque el legislador califica a este subrogado penal como un mecanismo sustitutivo, la prisión domiciliaria guarda considerables diferencias con la pena de prisión intramuros. En primera instancia, aunque ambas imponen un límite al derecho de locomoción de los condenados, la prisión tiene un carácter más intrusivo dentro de su ámbito personal por parte de las autoridades carcelarias. Dentro de los establecimientos penitenciarios existen cierto tipo de normas y obligaciones tales como el reglamento interno, la regulación de las visitas o comunicaciones o la obligación de trabajar. Éstas, afectan la manera en la que los individuos purgarán su sanción, a diferencia de si lo hacen en su domicilio, donde los controles son más laxos y se goza de más autonomía y libertad permitiéndole determinar su día a día ${ }^{70}$.

Así pues, la prisión domiciliaria es una pena privativa de la libertad, donde el condenado puede cumplir la ejecución de la condena en su lugar de residencia o morada, o en el lugar que el juez le

68. ARBOLEDA y RUIZ, Manual, cit. nota $n^{\circ}$ 28, p. 391.

69. PABÓN, Pedro. Manual, cit. nota $n \stackrel{0}{0} 56$, p. 622.

70. ARBOLEDA y RUIZ, Manual, cit. nota $n \cong 28, p .394$. 
determine, en lugar de hacerlo en establecimiento penitenciario, siempre que se cumplan los requisitos establecidos por el legislador.

Ahora bien, se entrarán a analizar los presupuestos que dispuso el legislador en la Ley 1709 de 2014 para poder acceder a la prisión domiciliaria analizando los cambios que introdujo. El nuevo código modifica el artículo 38 del Código Penal, estableciendo en éste en qué consiste la prisión domiciliaria como mecanismo sustitutivo de la prisión. Paralelamente, adiciona los artículos 38B, 38C, 38D relativos a los requisitos para acceder al subrogado, el control y la ejecución de la medida, respectivamente, los cuales antes de la reforma estaban contemplados en un único artículo. Por otra parte, se adicionan también los artículos 38E y 38G relativos a la redención de pena durante la prisión domiciliaria $\mathrm{y}$ al cumplimiento de la mitad de la condena para poder acceder al subrogado bajo análisis. Finalmente, cabe resaltar que se adiciona un artículo a la Ley 65 de 1993 el cual trata sobre la revocatoria de la prisión domiciliaria, así como de la detención domiciliaria. Es posible afirmar que el legislador quiso ser muy riguroso frente a las disposiciones referentes a este subrogado penal pues, en efecto, se adicionan varias y es minucioso en la redacción de las mismas.

Entrando en el análisis juicioso de las modificaciones que introduce la Ley 1709 , en primer lugar, vale mencionar, que el requisito objetivo cambia, pues con anterioridad a la reforma, la pena mínima por el delito cometido debía ser menor o igual a cinco años. En cambio, hoy, las personas que no tengan antecedentes y cuya pena mínima por el delito por el que fueron condenados no supere los ocho años de prisión, podrán acceder al subrogado.

Cabe resaltar que el requisito objetivo que contempla la norma, no hace referencia a la pena impuesta en sentencia, como anticipábamos en la introducción, sino que depende de la pena mínima que consagra el Código Penal para cada uno de los delitos. Entonces, si se trata del delito de lavado de activos (artículo 323 del Código Penal) que establece una pena mínima de prisión de 10 años, pero la persona acepta cargos en virtud a un preacuerdo y la pena impuesta queda en 5 años, de igual manera la pena mínima en abstracto supera los 8 años de prisión, imposibilitando el acceso al subrogado.
En lo atinente a este subrogado, que la pena mínima por el delito cometido haya aumentado de 5 a 8 años, permite pensar que una porción más amplia de la población reclusa tenga la posibilidad de acceder a prisión domiciliaria. En otras palabras, representa un aumento sustancial de casos en donde resultaría posible la concesión de este subrogado. De una u otra forma es posible afirmar, como se mostrará a continuación, que con la entrada en vigencia de la Ley 1709 , en efecto sí ha habido un aumento en el número de casos en los cuales se concede este subrogado penal, si bien a este hecho no se le puede atribuir únicamente la modificación frente a este requisito objetivo.

El día 29 de mayo del presente año se realizó una sesión de trabajo de campo en donde se analizó el archivo completo que contenía todas las domiciliarias tramitadas en el Juzgado 18 de Ejecución de Penas y Medidas de Seguridad de Bogotá, durante el año 2013. Del conteo realizado, se evidenció que el año pasado se concedió en 12 casos, únicamente, este subrogado penal, mientras que fue negado en 49 casos. Asimismo, con base a revisiones de consolidados numéricos de solicitudes otorgadas por este mismo juzgado en el mes de febrero y el mes de marzo $^{71}$, fue posible constatar que en febrero se concedieron 4 prisiones domiciliarias y 24 en el mes de marzo, para un total de 28. Esta información permite concluir que desde la entrada en vigencia de la Ley 1709 de 2014, en un transcurso de sólo dos meses, se han concedido en un mismo despacho más del doble de prisiones domiciliarias que en la totalidad del año inmediatamente anterior.

De la mano del cumplimiento de las obligaciones mediante caución, el cual es un requisito de mero trámite, el legislador previo a la reforma del 2014, no se percató de la evidente trasgresión del derecho a la igualdad que implicaba la existencia de ese vínculo ineludible entre la capacidad económica del sentenciado y la forma de ejecución de la pena, puesto que sólo se tendría acceso a la pena sustitutiva si se contaba con los recursos económicos que salden la garantía exigida ${ }^{72}$.

71. Ver Anexos 1 y 2

72. PABÓN, Pedro. Manual, cit. nota n o 56, p. 625. 
Si bien las penas pecuniarias no tienen el mismo carácter invasivo que sí poseen las penas privativas de la libertad, por un lado se hace evidente "el profundo efecto clasista"73, pero además tiene un impacto necesariamente más negativo en el condenado que no tenga los medios para pagar dicha pena. Para las clases más pudientes, la consecuencia de pagar una pena pecuniaria no acarrea mayores consecuencias; su patrimonio se reduce un poco pero, más allá de eso, su situación no resulta tan complicada. Adicionalmente, hay que introducir un concepto importante: la corrupción. Además de contar con los medios para poder pagar la pena pecuniaria, inclusive, los más pudientes podrían librarse de pagarla en su totalidad o sencillamente no pagarla, en virtud de este fenómeno. Lo anterior sobre todo en contextos como el colombiano donde siempre hay quien quiere lucrarse de manera indebida. En cambio, para aquella vasta porción de la población que no cuenta con los recursos para pagar las penas pecuniarias, esta pena "constituye la causa de serias complicaciones, debido a las limitaciones y privaciones de todo orden que aquella ocasiona al condenado y a su familia (...) en caso de no poder pagar, la sanción asume su carácter penal en la extensión más amplia del término"74. En síntesis, la igualdad se ve trasgredida desde el momento en que el sistema penal empezó a implementar el uso de penas pecuniarias y multas ${ }^{75}$.

Continuando con las modificaciones que introdujo la Ley 1709 , otro aspecto que vale la pena mencionar es que antes de la reforma, el artículo 38 del Código Penal contenía la prohibición del grupo familiar, en el siguiente tenor:

73. RUSCHE, George y KIRCHHEIMER, Otto, Pena y estructura, Traducción de Emilio García Méndez, Bogotá: Editorial Temis S.A., 1984, p. 213.

\section{RUSCHE y KIRCHHEIMER Pena, cit. nota $n^{\circ}$ 77, p. 214.}

75. Sobre el cambio de la multa como pena principal, oportuna la cita Rusche y Kirchheimer directamente relacionada al objeto de estudio (discriminación económica): "De este modo, quienes poseían dinero suficiente para pagar, podían comprar la exención de las penas; aunque los condenados indigentes (que constituían la gran mayoría en esos tiempo difíciles) estaban incapacitados para salvarse del tratamiento riguroso al que eran sometidos" anticipando así un criterio de discriminación y de eventual privación de derechos como consecuencia de la imposibilidad económica. RUSCHE y KIRCHHEIMER, Pena, cit. $\operatorname{nota}^{\mathrm{N}} \stackrel{\mathrm{o}}{7} \mathrm{7}, \mathrm{pp} .18$ y 19 la ejecución de la pena privativa de la libertad se cumplirá en el lugar de residencia o morada del sentenciado, o en su defecto en el que el Juez determine, excepto en los casos en que el sentenciado pertenezca al grupo familiar de la víctima (...).

La reforma establece un artículo para la ejecución de esta medida y traslada acá la excepción de cumplimiento de la pena privativa de la libertad en el lugar de residencia, cuando la víctima también resida ahí. De esta manera, la reforma adiciona el artículo 38D que frente a este punto reza así:

Artículo 38D. Ejecución de la medida de prisión domiciliaria. La ejecución de esta medida sustitutiva de la pena privativa de la libertad se cumplirá en el lugar de residencia o morada del sentenciado, excepto en los casos en que este pertenezca al grupo familiar de la víctima (...).

Por otro lado, el artículo 38 del Código Penal, antes de la reforma establecía como segundo presupuesto para la concesión de la prisión domiciliaria, que fuera posible comprobar, mediante su desempeño personal, laboral, familiar o social, que el condenado no pondría en peligro a la comunidad ni eludiría el cumplimiento de la pena. Lo anterior "a partir de pautas objetivas, racionales, ponderadas, en torno a la probable conveniencia de sustituir la pena, y desarrollar de esta manera los principios de proporcionalidad, razonabilidad y necesidad"76. Dentro de la voluntad del legislador estuvo eliminar este presupuesto del artículo 38 del Código Penal, sin embargo, sí se hace énfasis en el concepto del arraigo familiar y social.

Así pues, la reforma del 2014 introduce como nuevo requisito para conceder el subrogado bajo análisis, que se demuestre el arraigo familiar y social del condenado. Según el profesor Velásquez, el término del arraigo, introducido por el legislador colombiano resulta "rebuscad[o] e indeterminad[o]" pero que a grandes rasgos comprende maciza fijación que tiene un individuo frente a una cuestión en particular. Así, para cumplir con el requisito impuesto por

76.VELÁSQUEZ, Fernando, Manual de Derecho penal, parte general, Medellín: Comlibros, p. 1053. 
la ley, el condenado debe demostrar que tiene una sólida fijación respecto a las cuestiones específicas de la familia y la sociedad. "Más específicamente, el arraigo es una cuestión que suele saltar y estar presente en el momento en que por alguna razón de fuerza mayor una persona debe dejar su residencia, su patria, sus hábitos y costumbres para permanecer en otro lugar totalmente distinto, extrañando todo aquello que hacía o veía ${ }^{77 "}$.

En este punto es menester retomar los datos arrojados por el trabajo de campo realizado el día 24 de abril de 2014, respecto al número de casos en los que fue concedida la prisión domiciliaria como sustitutiva de la pena de prisión para los meses de febrero y marzo. Lo anterior, con el fin de explicar la razón por la cual hay un cambio tan drástico en el número domiciliarias concedidas de febrero a marzo. Como se mencionó anteriormente, para el mes de febrero, en el Juzgado 18 de Ejecución de Penas y Medidas de Seguridad de Bogotá, fueron concedidas 4 domiciliarias, mientras que en marzo fueron concedidas 24. Algo similar ocurrió en el juzgado 1ํo de Ejecución de Penas y Medidas de Seguridad, donde en el mes de febrero se concedieron 5, mientras que en el mes de marzo en 20 casos se concedió la medida. Ambas juezas afirman que lo anterior sucedió de tal manera, ya que en el mes de febrero los condenados que solicitaron el subrogado no poseían los documentos pertinentes para demostrar el arraigo familiar y social. En cambio, en el mes de marzo, con la posibilidad tangible de mostrar el arraigo, se conceden las domiciliarias tanto para las solicitudes realizadas en el mes de febrero como para aquellos casos de marzo que, a sabiendas que los jueces están siendo rigurosos con dicho requisito, obtienen los documentos necesarios.

Dadas las circunstancias actuales de los establecimientos carcelarios en Colombia, la existencia de un subrogado como lo es la prisión domiciliaria revela a leguas la necesidad de poner en un segundo plano las celdas y en cambio hacer prevalecer el domicilio. No obstante, mejorar las condiciones intramurales no constituye la única labor que recae sobre el Estado. En este sentido, la normatividad

77. ARBOLEDA y RUIZ, Manual, cit. nota $n \stackrel{0}{2} 28, p .396$.

78. PABÓN, Pedro. Manual, cit. nota n ำ56, p. 626. impuesta por el legislador debe estar sujeta a "contenidos criminológicos claros"8", que propendan también por lograr una efectiva resocialización y rehabilitación del sentenciado.

Ahora bien, vale la pena mencionar la dimensión del artículo 28 de la Ley 1709 que adiciona el artículo 38G a la Ley 599 de 2000, pues este proporciona una nueva medida: que sea posible cumplir la ejecución de la pena privativa de la libertad en el lugar de residencia cuando la persona haya cumplido la mitad de la condena, exceptuando (al igual que como se explicó previamente), aquellos casos donde el sentenciado pertenezca al grupo familiar de la víctima. Si bien para efectos de la concesión de este subrogado quedan excluidos los delitos incluidos dentro del artículo $68 \mathrm{~A}$, este mismo artículo en el parágrafo segundo establece que no tendrá aplicación cuando se trate de lo dispuesto en el artículo 38G. En el mismo artículo se encuentran enunciados los delitos que quedan excluidos para este beneficio. Adicionalmente, la norma jurídica en cita establece que se debe cumplir con los presupuestos 3 y 4 del artículo $38 \mathrm{~B}$, es decir: demostrar el arraigo familiar y social del condenado y garantizar mediante caución el cumplimiento de ciertas obligaciones.

Efectivamente, como lo constataron las juezas $1^{\mathfrak{a}}$ y 18 de Ejecución de Penas y Medidas de Seguridad, desde que entró a regir la Ley 1709 se empezó a solicitar en buena medida este subrogado por parte de los internos. De igual manera, como se pudo comprobar en el trabajo de campo realizado por el Grupo de Prisiones de la Universidad de los Andes, tanto en el Establecimiento Penitenciario y Carcelario "La Modelo" como del Establecimiento Carcelario "El Buen Pastor", ambos de la ciudad de Bogotá, muchos internos que a la entrada en vigencia de la Ley 1709 ya habían cumplido con un poco más de la mitad de la condena, pero que no necesariamente cumplían con el requisito temporal de las $3 / 5$ partes de la misma para acceder a la libertad condicional, se apresuraron a solicitar este subrogado penal bajo esta nueva modalidad.

Los resultados en la Cárcel Nacional Modelo muestran que para el año 2014, 244 internos se encontraban en prisión domiciliaria: 
Gráfica 2. Población en prisión domiciliaria E.C. Bogotá. 2014

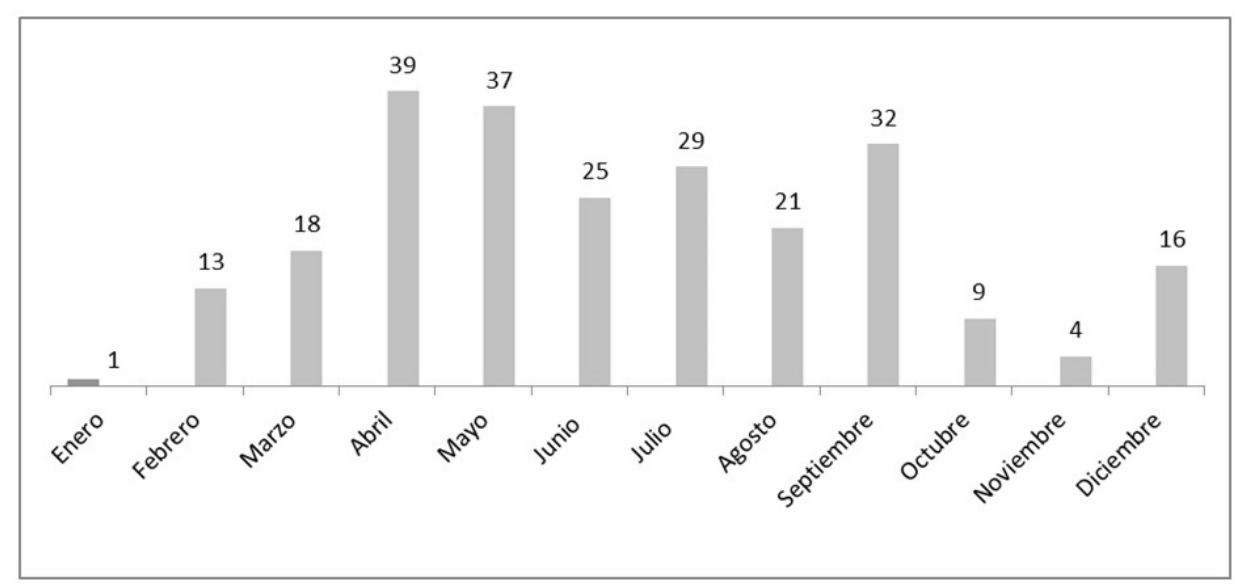

Fuente: Jurídica E.C. Bogotá (Informe Ley 1709 de 2014)

Que el legislador haya introducido esta nueva modalidad de prisión domiciliaria muestra, una vez más, la necesidad de encontrar una solución a la grave crisis del hacinamiento carcelario por la que atraviesa nuestro país en la actualidad. Adicionalmente, desde un punto de vista progresista, es posible afirmar que constituye un incentivo más, por lo menos para muchos condenados, cuya situación al interior de la cárcel es crítica, para poder cumplir su pena por fuera del establecimiento más rápidamente.

Sin embargo, es posible detectar una fuerte crítica hacia las disposiciones que regulan la concesión de este subrogado bajo la mencionada modalidad. El artículo 68 A establece que aquellas personas que hayan sido condenadas por delitos dolosos contra la Administración Pública no tendrán derecho a los subrogados penales o beneficios. Insistimos, el mismo artículo determina que ésta disposición no aplica cuando se trata del subrogado consagrado en el artículo 38G. Lo anterior se traduce en que cuando un servidor público cometa alguno de los delitos incluidos en el Título $\mathrm{XV}^{79}$ del Código Penal, que vale resaltar no son pocos, puede "librarse" de purgar su condena intramuros y en cambio hacerlo en su domicilio. Lo anterior resulta bastante cuestionable teniendo en cuenta el contexto en el que se ubica Colombia frente al manejo del sector público y las actuaciones de

79. Delitos contra la administración pública. los funcionarios colombianos. Los delitos que comenten los servidores públicos contra la Administración Pública son innumerables y este sector se caracteriza por su ambiente poco transparente.

Así, como informa el diario El País ${ }^{80}$, según el Observatorio de Transparencia y Anticorrupción, los delitos que más se cometen en Colombia contra la administración pública son los siguientes: el delito de peculado elevado a un $45.2 \%$, el delito de cohecho con un $31.8 \%$, el delito de concusión representado por $11.7 \%$, el delito de prevaricato con un $6.4 \%$ y celebración indebida de contratos representando el 3.8\%.

Adicionalmente, en sentencia C-073 de 2010, la cual hace referencia a la C-762 del 2002, se anota que el establecer un listado de delitos para los cuales se excluye la concesión de subrogados penales y beneficios administrativos, es una decisión que está en cabeza del legislador, cuyo objetivo está encaminado a poner en práctica el derecho a la justicia de las víctimas, en contra de quienes se cometió una conducta que afecta gravemente bienes jurídicamente protegidos. Así, lo que esto significa es que "la eliminación de beneficios y subrogados penales responde al

80. "Mayoría de sanciones impartidas en Colombia son de delitos por corrupción". Disponible on line: http://www.elpais.com. co/elpais/colombia/noticias/mayoria-sanciones-impartidascolombia-son-por-delitos-corrupcion (Página de internet consultada por última vez el 5 de agosto de 2014). 
diseño de una política criminal que, interpretando la realidad del país, está direccionada a combatir las peores manifestaciones delictivas (...)"

Como se venía esbozando previamente, teniendo en cuenta los problemas socio económicos en los que se ve inmersa Colombia, resulta sumamente cuestionable que servidores públicos que deberían actuar en beneficio del Estado y en quienes recae una de las mayores responsabilidades para con el país, cuenten con la posibilidad de purgar su pena en la comodidad de sus domicilios. Además, como bien afirma el profesor Pabón Parra,

la prisión sustitutiva se ha convertido en expediente, utilizado en todos los casos por los abogados defensores para procurar que su representado logre eludir, a cualquier precio, el cumplimiento intramural de la pena (...). Así, la concesión de sustitución se ha convertido en intensa fuente de corrupción ${ }^{82}$.

Teniendo en cuenta estas palabras, la capacidad económica de esta porción de la población, como lo son los servidores públicos, además de todo lo mencionado anteriormente, contribuirán a que el círculo de la corrupción se vuelva cada vez más grande.

Por último, en referencia a la vigilancia y el control de esta pena sustitutiva, cabe mencionar que antes de la reforma introducida por la Ley 1709, el legislador dio preponderancia a la mera vigilancia para garantizar a toda costa el cumplimiento de la prisión domiciliaria. En este punto la redacción del legislador descuidó los costos que implica la vigilancia en el lugar de domicilio, adscribiendo dichas funciones de vigilancia y operativas únicamente al INPEC. Si bien las disposiciones de la reforma del 2014 facultan al INPEC para celebrar convenios con la Policía Nacional, cuando no haya guardia suficiente para verificar a las personas que se acojan a prisión domiciliaria, ésta facultad ya había sido propuesta en el contenido original de la Ley 1564 de 2010, pero no prosperó en el trámite legislativo ${ }^{83}$.

81. Sentencia C-073 de 2010. MP: Humberto Antonio Sierra Porto.

82 PABÓN, Pedro. Manual, cit. nota $n^{\circ}$ 56, p. 623.

83. PABÓN, Pedro. Manual, cit. nota n ํ56, p. 626.
Para que efectivamente se cumplan los fines de esta medida, es importante que haya una vigilancia y control efectivo sobre los condenados. En este punto es relevante recalcar dos cosas. En primer lugar, si bien la facultad de celebrar convenios entre el INPEC y la Policía Nacional, puede ser útil en la medida que reviste de capacidad a una entidad que proporciona una gran cantidad de gente que puede involucrarse en la vigilancia, en la práctica es posible afirmar que los mecanismos de vigilancia electrónica, son los que realmente proporcionan el control. Como se reveló en entrevistas con las Juezas $1^{\mathrm{a}}$ y 18 de Ejecución de Penas y Medidas de Seguridad de Bogotá, la mayoría de juzgados están concediendo la prisión domiciliaria siempre con un mecanismo de vigilancia electrónica ${ }^{84}$.

En síntesis, la prisión domiciliaria como sustitutiva de la pena de prisión intramural es en sí un "paliativo con visos de privilegio", cuyo fin principal recae sobre la necesidad de atacar el problema del hacinamiento carcelario. Sin embargo, no se puede dejar de lado que éste no es el único problema del cual se debe encargar el Estado. En consecuencia, si bien la reforma introduce nuevas disposiciones que abogan por un punto intermedio entre el fin de descongestionar los establecimientos penitenciarios y el fin de la resocialización y la rehabilitación, es posible sostener que la voluntad del legislador fue un poco laxa, como se evidencia en el caso de los delitos contra la Administración Pública.

\section{CRITERIOS JUDICIALES DE INTERPRETACIÓN DE LA LEY 1709}

En este acápite analizaremos algunos problemas de interpretación que se han originado con la entrada en vigencia de la Ley 1709 de 2014, con base en las decisiones judiciales proferidas hasta el momento.

84. Artículo 38D. Ejecución de la medida de prisión domiciliaria. La ejecución de esta medida sustitutiva de la pena privativa de la libertad se cumplirá en el lugar de residencia o morada del sentenciado, excepto en los casos en que este pertenezca al grupo familiar de la víctima.

El juez podrá ordenar, si así lo considera necesario, que la prisión domiciliaria se acompañe de un mecanismo de vigilancia electrónica.

El juez podrá autorizar al condenado a trabajar y estudiar fuera de su lugar de residencia o morada, pero en este caso se controlará el cumplimiento de la medida mediante un mecanismo de vigilancia electrónica. (Subraya por fuera del texto). 


\subsection{Ley penal en el tiempo, favorabilidad y lex tertia}

Por regla general, las leyes rigen hacia el futuro, regulando los hechos $y$ actos que se produzcan a partir de su vigencia. Sin embargo, en materia penal, rige el principio de favorabilidad que es una modificación a esta regla y permite que se aplique la ley más favorable a los intereses del reo, ora por retroactividad, ya por ultractividad.

La favorabilidad de la ley penal se encuentra establecida tanto en instrumentos internacionales ${ }^{85}$, como en las legislaciones locales a nivel mundial ${ }^{86}$. Inspirados en este principio, la Judicatura ha desarrollado los parámetros de la lex tertia.

La lex tertia es una combinación de leyes, que en definitiva crea una tercera ley, a partir de un ejercicio de interpretación judicial - ajeno al legislativo -, con base en las disposiciones más favorables contenidas en dos leyes que regulan el mismo tema. Es decir, hace aplicación retroactiva de una ley y aplicación ultractiva de otra, con base en sus partes más favorables. La doctrina, mayoritariamente, ha rechazado este ejercicio ${ }^{87}$, con base en los principios

85. Cfr. Artículos 9 de la Convención Americana de Derechos Humanos, 15-1 del Pacto Internacional de Derechos Civiles y Políticos y 24-2 del Estatuto de la Corte Penal Internacional.

86. Cfr. Artículos 2ํo (común) de los Códigos Penales de Alemania, Argentina, Brasil, Ecuador, España, Italia, 6º del Código Penal de Colombia, 112-1 del Código Penal de Francia y 8o-b del Código Penal de Puerto Rico.

87. LUZÓN, Diego-Manuel, Curso de Derecho Penal, parte general, Madrid: Universitas, 2002, p 187. CEREZO MIR José, Curso de Derecho Penal Español, parte general, Madrid: Léenos, 1997, p. 234. MUÑOZ, Francisco y GARCÍA, Mercedes, Derecho Penal, parte general, Valencia: Tirant to Blanch, 2002 p. 144. NOVOA, Eduardo, Curso de Derecho Penal Chileno, Santiago: Editorial Jurídica de Chile, 1966, p. 201. BASCUÑÁN, Antonio, "La Ley Penal", Revista de Derecho de la Universidad Adolfo Ibáñez, $N^{\circ}$ 2 (2005), pp. 369 a 371. CURY, Enrique, Derecho Penal, parte general, Santiago: Universidad Católica de Chile, 2005 p. 229. POLITOFF, Sergio; MATUS, Jean Pierre; RAMÍREZ, María Cecilia, Lecciones de Derecho Penal Chileno, parte general, Santiago: Editorial Jurídica de Chile, 2004, p. 131. En posición contraria, BUSLOS RAMÍREZ, Juan, Manual de Derecho Penal, parte general, Barcelona:, 1994, pp. 179 y ss. (Esta referencia fue extraída de BALDOMINO, Raul, (Ir)retroactividad de las modificaciones a la norma complementaria de una Ley Penal en Blanco, Revista Política criminal, vol.4 no.7, Santiago: 2009). Sobre el tema, ver también JIMENEZ DE ASUA, Luis, Tratado de Derecho Penal, Buenos Aires: Losada, 1964, p. 63: "para hallar la solución más favorable para el delincuente no es posible combinar varias leyes; es decir, que no es dable dividir la ley antigua y la nueva en varias partes para aplicar al acusado las disposiciones más benignas de la una y de la otra al mismo tiempo, sino que, debiendo hacer uso el Juez de la ley más benigna, no puede darse al reo un trato jurídico que, por ser derivado de las dos, no es propio de la nueva ni de la antigua. Lo contrario sería autorizar al magistrado para crear una tercera ley-con disposiciones de la de legalidad y seguridad jurídica y su eventual quebranto, a partir de esta dinámica judicial. En el mismo sentido, la jurisprudencia de la Sala de Casación Penal de la Corte Suprema de Justicia había rechazado esta posibilidad. En sentencia del 10 de diciembre de 1981, se expresó al respecto:

Quiere esto significar que la ley cuya favorable aplicación demandan la Constitución y los principios rectores del derecho, es concretamente aquella disposición o aquel conjunto de disposiciones que, formando parte de una cualquiera de las que se confrontan, regulan normativamente con mayor beneficio para el interesado, el hecho humano o jurídico generador del conflicto.

Lo que no resulta valedero, como lo advierte la doctrina universal y como esta misma corporación lo ha manifestado (ver casación de julio 11 de 1952 y auto de mayo 21 de 1981), es tomar de una ley solamente lo que en determinado aspecto favorezca al procesado y de la otra lo que desde otro lo beneficie igualmente, porque en tal hipótesis el juzgador no estaría aplicando de las leyes enfrentadas la más favorable, sino creando una tercera con pedazos de aquellas, con lo que se convertiría arbitrariamente en legislador ${ }^{88}$

Este criterio fue reiterado en la sentencia del 13 de julio de 1994 (Radicado 8539), como se anota a continuación:

(...) la aplicación de tales preceptos es integral sin que sea permitido tomar de cada una de las codificaciones en comparación lo que favorece y

precedente y de la posterior-, con lo cual se arrogaría funciones legislativas que no tiene. En suma: ha de aplicarse la ley más favorable, en su conjunto, aunque en algún extremo concreto contenga disposiciones más rigurosas, porque no puede hacerse la condición del acusado mejor de lo que autorizan una u otra de las dos legislaciones". Por la doctrina local, oportuna la cita del profesor Fernando Velásquez, en el siguiente sentido: "No obstante, la tarea se complica cuando se confrontan leyes complejas como los códigos penales que brindan al interesado la posibilidad de beneficiarse al mismo tiempo de dos o más leyes en conflicto, siempre y cuando se tomen preceptos íntegros de cada una de ellas para aplicarlos al caso preciso, pues es obvio que puede resultar perjudicado por unos aspectos y favorecidos por otros. Para que esto último sea viable debe tratarse de leyes complejas divisibles, que permiten tomar lo más favorable de cada una de ellas y posibilitan la ultra o retroactividad de la ley en bloque (lex tertia); en cambio, las indivisibles, al no poder fraccionarse, no autorizan al juzgador a tomar fragmentos de una y otra para resolver el caso, pues ello equivaldría a crear una tercera ley, lo que está prohibido" Velásquez, Manual, cit. nota $n^{\circ} 80$, p. 299

88. M.P. Alfonso Reyes Echandía. 
desechar lo que perjudica, pues ello equivaldría a crear arbitrariamente una tercera norma, o ley tercia, especial al caso juzgado ${ }^{89}$.

No obstante lo anterior, a partir del año $2001^{90}$, esa Corporación habilitó la conjugación, conjunción, o combinación de disposiciones normativas, creando una tercera ley, permitiéndole al juzgador "tomar de una norma lo favorable y desechar lo odioso, así como tomar de la otra u otras lo benigno y dejar de lado lo desfavorable" ${ }^{\prime 11}$. Con base en lo anterior, en la elaboración de este ejercicio intelectivo se deben tener en cuenta los siguientes postulados ${ }^{92}$ :

(i) Que los preceptos jurídicos que se pretenden conjugar o combinar, tal como acontece en materia de favorabilidad, deben ser "perfectamente deslindables en su concepción teórica y práctica, aunque haga parte de un todo orgánico", es decir, que resulten escindibles de la norma compleja y divisible que los contiene, siempre y cuando conserven su identidad y sentido jurídico, tal como ocurre con las penas principales de prisión o multa, previstas para cada tipo penal en concreto.

\section{M.P. Jorge Carreño Luengas}

90. Cfr. Sentencia del 3 de septiembre de 2001, Radicado: 16837, M.P. José Aníbal Gómez Gallego. Curiosamente, en sentencia del 12 de julio de 2000 (Radicado 14987), esa Corporación, con ponencia del mismo Magistrado, consideró que: "Sin embargo, la favorabilidad, como supone una sucesión de leyes en el tiempo, debe proclamarse de estatutos o normas completas, pues no podría cuartearse el contenido de una y otra para crear una tercera que no ha previsto el legislador, manera sutil o abierta de sustituirlo arbitrariamente (lex tertia).

91. "'Lo importante es que identificada una previsión normativa como precepto, cualquiera sea su conexión con otras, se aplique en su integridad, porque, por ejemplo, no sería posible tomar de la antigua ley la calidad de la pena y de la nueva su cantidad, pues un tal precepto no estaría clara y expresamente consagrado en ninguno de los dos códigos sucesivos, razón por la cual el juez trascendería su rol de aplicador del derecho e invadiría abusivamente el ámbito de la producción de normas propio del legislador. A esta distinción de preceptos para efectos exclusivos de favorabilidad (ella supone una ficción), de modo que hipotéticamente puedan separarse en su aplicación, contribuye, verbigracia, el espíritu del artículo 63 del estatuto vigente, según el cual el juez podrá suspender la ejecución de la pena privativa de la libertad y exigir el cumplimiento de las otras (multa e inhabilitación), sin que por ello se convierta en legislador o renegado de la respectiva disposición sustantiva que obliga la imposición de las tres penas como principales y concurrentes, pues la decisión judicial no es norma sino derecho aplicado." Sentencia del 3 de septiembre de 2001, cit. nota $n^{\circ} 113$.

92. Cfr. Sentencia del 12 de marzo de 2014, Radicado: $25817-$ 61-01-198-2013-80171-01, M.P. Israel Guerrero Hernández, Tribunal Superior de Cundinamarca - Sala Penal. (ii) Una vez se identifiquen las previsiones normativas que se pretenden conjugar, éstos deben ser tomados íntegramente, lo cual implica que no resulta procedente la combinación parcial de disposiciones normativas, toda vez que ello representaría una invasión del juez en la órbita de competencia exclusiva del legislador, y tratándose de un problema de aplicación de la ley y no de producción legislativa, debe estar siempre dentro de los límites de la legalidad, ya que, a manera de ejemplo, ilustra la jurisprudencia, no sería posible tomar de la antigua ley la calidad de la pena y de la nueva su cantidad, pues un tal precepto no estaría clara y expresamente consagrado en ninguno de los dos códigos sucesivos, razón por la cual el juez trascendería su rol de aplicador del derecho e invadiría abusivamente el ámbito de la producción de normas propio del legislador.

Esta tesis se ha mantenido en las siguientes providencias de la misma Corporación:

(i) Radicado 14183 (31-01-02), MM.PP. Jorge E. Cordoba Poveda y Carlos Augusto Gálvez Argote

(ii) Radicado 19445 (06-10-04), M.P. Álvaro Orlando Pérez Pinzón

(iii) Radicado 21044 (19-01-05), M.P. Jorge Luis Quintero Milanés

(iv) Radicado 23272 (27-08-07), M.P. Sigifredo Espinosa Pérez

(v) Radicado 29692 (20-01-10), M.P. Alfredo Gómez Quintero

(vi) Radicado 33655 (07-04-10), M.P. Jorge Luis Quintero Milanés

(vii) Radicado 26916 (04-11-10), M.P. Maria del Rosario González de Lemos

(viii) Radicado 28143 (29-06-11), M.P.

Maria del Rosario González de Lemos

(ix) Radicado 35512 (27-07-11), M.P. Augusto J. Ibáñez Guzmán

(x) Radicado 35900 (11-05-11), M.P. Jose Leónidas Bustos Martínez

Ahora bien, específicamente sobre la aplicación de la lex tertia, en virtud de la entrada en vigencia de la Ley 1709 de 2014, la respuesta de la Corte Suprema de Justicia ha sido negativa, por las siguientes razones: 
Bajo estas premisas, deviene improcedente la propuesta formulada por el togado para que por la vía de la favorabilidad se acceda a otorgársele a su representada la detención preventiva domiciliaria con base en el artículo 23 de la nueva ley 1709 de 2014 que extendió el beneficio a las conductas punibles cuya pena mínima prevista en la ley sea de ocho (8) años de prisión o menos y simultáneamente se aplique el modificado artículo 38 de la Ley 599 de 2000, que no restringe el subrogado, como lo hace el artículo 23 citado a delitos como el Concierto para Delinquir agravado.

Lo anterior, ni más ni menos, significa que se confeccione una tercera norma que prevea unos requisitos para la prisión domiciliaria de una manera distinta a como el instituto fue concebido por el legislador del 2000 y a como lo define la ley actual, desarticulando y desintegrando su formulación legal.

$\mathrm{Y}$ es que no puede predicarse que cada uno de los requisitos que condicionan el otorgamiento del sustituto, puedan ser estimados aisladamente como si constituyeran una previsión normativa o un precepto con individualidad jurídica del que se pudiera pretender su aplicación favorable, sin lesionar el espíritu que animó al legislador del año 2000 y del 2014 a excluirlo para delitos como el Concierto para delinquir agravado ${ }^{93}$.

Es decir, que no puede combinarse el requisito objetivo consagrado en la ley 1709 de 2014, de manera retroactiva, por resultar más favorable en virtud del aumento del quantum punitivo, desligando la prohibición de delitos consagrada en el nuevo estatuto, cuya ampliación limita la concesión de subrogados. Esto por cuanto ese fue el espíritu del legislador y la interpretación judicial en sentido contrario, invadiría esta órbita, atentando contra la separación de poderes, la reserva legislativa y la seguridad jurídica.

\subsection{Derogatoria "tácita" de los artículos 26 de la ley 1121 de 2006 (extorsión) y 199 de la Ley 1098 de 2008}

Por otra parte, otro elemento que introdujo la reforma al Código Penitenciario y Carcelario fue la supresión de los delitos consagrados en el

93. Providencia del 24 de febrero de 2014, Radicado: 34099. En el mismo sentido, providencia de la misma Corporación, Radicado: 42623, M.P. Gustavo Enrique Malo Fernández y sentencia del 12 de marzo de 2014, cit. nota $n^{\circ}-115$. artículo 68 A del Código Penal como excepciones para acceder a la libertad condicional. Dado que, de una u otra forma, establecer una serie de delitos que de entrada no permitan la revisión de un caso determinado, para acceder a un subrogado penal, constituye una limitación considerable, es posible afirmar que el objetivo del legislador, al excluir del ámbito de aplicación del artículo 68 A para la libertad condicional, es hacer más laxa su concesión.

No obstante, una ineludible confrontación de normas se desprende de la desvinculación del artículo 68 A del subrogado de la libertad condicional. La Ley 1121 de 2006, en su artículo 26 -reza así:

Cuando se trate de delitos de terrorismo, financiación de terrorismo, secuestro extorsivo, extorsión y conexos, no procederán las rebajas de pena por sentencia anticipada y confesión ni se concederán subrogados penales o mecanismos sustitutivos de la pena privativa de la libertad de condena de ejecución condicional o suspensión condicional de ejecución de la pena, o la libertad condicional (...).

Paralelamente, el artículo 199 del Código de la Infancia y la Adolescencia ${ }^{94}$ establece que:

Cuando se trate de delitos de homicidio o lesiones personales bajo modalidad dolosa, delitos contra la libertad, integridad y formación sexuales, o secuestro, cometidos contra niños, niñas y adolescentes, se aplicarán las siguientes reglas: (...) 8. Tampoco procederá ningún otro beneficio o subrogado judicial o administrativo, (...).

Las dos normas previamente señaladas, niegan la procedencia de la libertad condicional cuando se trata de algunos delitos en particular. Sin embargo, el problema radica en que algunos de aquellos delitos también hacen parte del artículo 68 A de la Ley 1709, pero que para efectos de la concesión de la libertad condicional no se aplicaría. Así pues, en el caso del delito de la extorsión, éste, está doblemente mencionado; tanto en el artículo 26 como en el 68 A. Lo mismo sucede en mención del Código de la Infancia y la Adolescencia respecto de los delitos contra la libertad, integridad y formación sexuales, los cuales el legislador también incluyó en el artículo

94. Ley 1098 de 2006. 
68 A. Ahora bien, de acuerdo con la redacción del artículo 107 de la Ley 1709, la misma deroga todas aquellas disposiciones que le sean contrarias.

Sobre la base de esta circunstancia surge la siguiente pregunta: ¿en virtud del artículo 107 de la Ley 1709 quedan derogados los artículos 26 de la Ley 1121 de 2006 y 119 del Código de la Infancia y la Adolescencia? Dicha pregunta ha suscitado un gran debate y cuestionamiento por parte de los operadores judiciales. Ciñéndose estrictamente a las normatividad, no sería osado afirmar que, en efecto, aquellas disposiciones previas que contrarían alguna norma de la Ley 1709 de 2014 quedan derogadas. Pese a lo anterior, no se hace tan evidente que en realidad los operadores jurídicos lo apliquen de esta manera en sus providencias. Lo anterior, por cuanto el Código de la Infancia y la Adolescencia ostenta una protección reforzada y un carácter especial frente a las víctimas, pues como lo establece el artículo 4o del mismo, las normas de en éste contenidas, se preferirán sobre las normas de cualquier otra ley. Es por esta razón que para efectos prácticos, el artículo 68 A que excluye determinados delitos, que no cobijan la libertad condicional, no puede derogar el artículo 199 o de lo contrario estaría pasando por encima de la especial protección de la que gozan los niños, niñas y adolescentes. Como sustento de lo anterior, la Juez 18 de Ejecución de Penas y Medidas de Seguridad de Bogotá ${ }^{95}$ ratificó que, por lo menos en su juzgado, se están negando varias condicionales cuando se trata de delitos contra menores.

En el mismo sentido, nuestra Corte Suprema de Justicia ${ }^{96}$ ha manifestado que los artículos 26 de la Ley 1121 de 2006 y 199 de la Ley 1098 de 2008, no fueron derogados tácitamente por la Ley 1709 de 2014, comoquiera que este fenómeno jurídico solo acontece cuando la disposición nueva no es conciliable con la anterior, lo que no ha ocurrido con estas normas jurídicas, ya que en el presente caso, la Ley 1709 dejó incólumes las disposiciones normativas que regulan la libertad condicional. Adicionalmente se argumenta que prevalece la norma de carácter especial sobre la general, por esa razón, las prohibiciones relacionadas se mantienen vigentes.

\section{Entrevista realizada el 24 de abril de 2014.}

96. Cfr. Sentencias del 29 de mayo de 2014, Radicado: 73770, M.P. José Luis Barceló Camacho y del 25 de junio de 2014, Radicado: 73914, M.P. Eugenio Fernandez Carlier

\section{CONCLUSIONES}

Como se evidencia en páginas precedentes, Colombia está atravesando una de las crisis del sistema penitenciario y carcelario más graves de la historia. El hacinamiento en los centros de reclusión es una de las manifestaciones más dramáticas de esta crisis; sin embargo, la sobrepoblación trae consigo otro tipo de problemas que incrementan la gravedad y preocupación de este asunto. Dentro de éstos se encuentran la carencia de infraestructura carcelaria, la casi inexistente prestación del servicio de salud, la insuficiencia del personal de guardia, la corrupción que reina dentro de las cárceles y las condiciones de salubridad en las que se vive al interior de las mismas.

Los subrogados penales se han entendido en Colombia como mecanismos que sustituyen la pena de prisión y se fundamentan en el concepto de la resocialización del delincuente. Con anterioridad a la entrada en vigencia de la Ley 1709 de 2014, la utilización de estas medidas surtía sus efectos, pues alguna porción de la población carcelaria se veía beneficiada por las mismas. Sin embargo, si bien su aplicación beneficiaba de manera particular a algunos individuos dado el contexto de sus casos, para efectos de resolver los problemas estructurales de la crisis por la que atraviesan los establecimientos carcelarios, una reforma era inminente; tanto los subrogados penales como la normatividad en general que regula lo atinente al sistema penitenciario y carcelario necesitaba una revisión por parte del legislador.

Teniendo en cuenta el contexto político y social del actual estado Colombiano, donde la inseguridad y la delincuencia son algunos de los postulados característicos del país, es posible afirmar que la crisis del sistema penitenciario no llega a estos niveles críticos, únicamente por la incapacidad económica que tiene el Estado para hacerle frente a la problemática; por su parte, es posible afirmar que en aras de proyectar un país que lucha por combatir la inseguridad y la delincuencia en las calles, ha dejado en un segundo plano muchos otros problemas que debe combatir. La solución de dar penas de prisión masivamente, constituye un mero mecanismo de eficacia simbólica por parte del Estado a su pueblo, pues le hace creer que en efecto se está trabajando por un país 
más seguro. Sin embargo, la envergadura de otras problemáticas no puede ser desatendida.

Es así como la Ley 1709 de 2014 introduce una nueva reforma que pretende hacerle frente a la grave crisis carcelaria. Particularmente y en lo que atañe el trabajo expuesto en páginas anteriores, la citada ley realiza varias modificaciones a los subrogados penales. Si bien la magnitud de crisis del sistema penitenciario sólo podrá ser resulta de manera efectiva a largo plazo y han transcurrido únicamente unos meses desde la entrada en vigencia de la Ley 1709 , se pueden traer a colación las siguientes conclusiones referentes a las modificaciones efectuadas frente a los subrogados penales.

En primer lugar, frente a la exclusión del pago de multas para acceder a los subrogados penales, queda zanjada esa trasgresión del derecho a la igualdad, debate que innumerables veces atravesó los recintos de la Corte Constitucional. Asimismo, es posible afirmar que una mayor cantidad de presos podrán acceder a los subrogados penales, ya que por un lado, la población imperante al interior de las cárceles es de escasos recursos y por otro, ésta era una de las razones más comunes para negarlos.

Por otra parte, al realizar un análisis de las modificaciones del artículo $68 \mathrm{~A}$, el concepto no resulta tan favorable como en el caso de la modificación de la multa. El nuevo artículo, no solo incluye una lista mucho más extensa de delitos que se excluyen para efectos de la concesión de subrogados penales, sino que en la práctica (por medio de las estadísticas del INPEC) se evidencia que los delitos que más se siguen cometiendo hacen parte de esta lista. No obstante, limitar el alcance del artículo en cuestión para determinados subrogados, suscita otro tipo de cuestionamientos. Tal es el caso de quienes cometen delitos contra la Administración Pública, que pueden acceder a la concesión de subrogados penales en razón de la no aplicación del artículo 68 A del Código Penal colombiano.

Ahora bien, del análisis efectuado sobre las modificaciones del subrogado de la libertad condicional, se concluyen principalmente tres puntos. En primera instancia, de la supresión de los delitos consagrados en el artículo 68 A como excepciones para acceder a la libertad condicional, es posible afirmar que el legislador busca hacer que la concesión de esta medida se torne un poco más laxa. En segundo lugar, si bien la reforma eliminó el término "gravedad" para realizar la valoración de la conducta punible, para efectos prácticos los operadores jurídicos no lo eliminan como lo revelan las entrevistas practicadas, así como la explicación teórica elaborada. Por último, la redacción del legislador del 2014, introduce una confrontación entre normas, cuya vigencia no queda clara, a pesar de los pronunciamientos judiciales anotados. Sobre este punto lo que se puede concluir es que si bien la Ley 1709 en su artículo 107 establece que la misma deroga todas aquellas disposiciones que le sean contrarias, los operadores jurídicos están aplicando las normas según el rango o protección especial que tengan. En otras palabras, según una ponderación del bien jurídico que se está protegiendo.

En lo atiente al subrogado de la suspensión condicional de la ejecución de la pena vale resaltar que la primera modificación introducida por la Ley 1709 es el cambio de 3 a 4 años respecto del requisito objetivo para poder acceder al mismo. Concluimos que si bien para ver los resultados prácticos de la modificación frente a este requisito objetivo, es necesario esperar qué tanto se vuelve a solicitar el subrogado una vez el proceso se encuentre en manos de los jueces de ejecución de penas, es muy probable que una porción más amplia de la población reclusa pueda solicitarlo ya que en una gran cantidad de casos, por superar los tres años, no se concedía el subrogado por parte de los jueces de conocimiento. Por otro lado, es posible afirmar que el legislador buscó darle un tinte más objetivo, puesto que el análisis subjetivo que implica revisar los antecedentes personales, sociales y familiares, solamente se lleva a cabo cuando existen antecedentes.

Frente a la prisión domiciliaria, se extraen dos conclusiones que se puede clasificar como de carácter positivo frente a la entrada en vigencia de la norma jurídica. La pena mínima por el delito cometido aumentó de 5 a 8 años con la modificación introducida por la reforma, lo cual permite concluir que una porción más amplia de la población reclusa puede solicitar este subrogado. En efecto, los datos recogidos en el trabajo de campo evidencian que en el transcurso de dos meses desde la entrada en vigencia de la Ley 1709, se han concedido en un mismo despacho más del doble de prisiones domiciliarias, que en la totalidad del año justamente anterior. Adicionalmente, 
se introduce una nueva especie de prisión domiciliaria que permite acceder a la misma, una vez el condenado o la condenada, hayan superado el tiempo de privación de la libertad, equivalente a la mitad de la pena impuesta.

Insistimos, de las modificaciones en la Ley 1709 respecto a los subrogados penales es, quizás, en la prisión domiciliaria que el legislador introduce una de las figuras más novedosas. Esta nueva medida la cual permite cumplir la ejecución de la pena privativa de la libertad en el lugar de residencia, cuando la persona haya cumplido la mitad de la condena, vislumbra la intención del legislador por introducir medidas que tengan impacto sobre la disminución de la sobrepoblación carcelaria.

Finalmente, el énfasis que hace el legislador sobre el arraigo familiar y social y la utilización de mecanismos de vigilancia electrónica para garantizar el cumplimiento de la prisión domiciliaria permiten concluir que si bien el legislador busca hacerle frente a la crisis del sistema penitenciario y carcelario, no lo hace dejando de lado otros presupuestos de importancia.

Con la entrada en vigencia de la Ley 1709 de 2014, los mecanismos de vigilancia electrónica quedaron únicamente como accesorios al subrogado penal de la prisión domiciliaria $\mathrm{y}$ se elimina su vigencia como subrogado independiente. Dicha movida por parte del legislador es bastante cuestionable teniendo en cuenta que uno de los objetivos de la citada ley descongestionar las cárceles del país. Anteriormente, al estar formulados como un subrogado penal independiente, constituían un mecanismo adicional al cual se podía acceder. No obstante, es pertinente resaltar que si la reforma no hubiera eliminado este subrogado como uno independiente, los presupuestos que deben concurrir para que se conceda la prisión domiciliaria serían prácticamente iguales a los que deben concurrir para acceder a los mecanismos de vigilancia electrónica. Así, dicha modificación está orientada en términos de practicidad.

En síntesis, la Ley1709 de 2014 en aras de atacar la grave crisis del sistema penitenciario y carcelario introdujo modificaciones significativas en lo atinente a los subrogados penales. Sin embargo, quedan ciertos vacíos frente a normatividad previa así como cuestionamientos que surgen a raíz de dichas modificaciones. Teniendo en cuenta algunos datos arrojados por el trabajo de campo realizado es posible afirmar que a medida que vaya avanzando el tiempo, por lo menos éstas modificaciones sí tendrán un impacto positivo en la descongestión de las cárceles del país. 


\section{BIBLIOGRAFÍA}

- ALDERETE, Rubén. La libertad condicional en el código penal argentino, Buenos Aires: LexisNexis, 2007.

- Alemania, Código Penal.

- ARBOLEDA, Mario y RUIZ, José Armando. Manual de derecho penal, partes general y especial conforme con el nuevo código penal, Bogotá: Leyer, 2002.

- ARGEnTinA, Código Penal.

- BALDOMINO, Raul, (Ir)retroactividad de las modificaciones a la norma complementaria de una Ley Penal en Blanco, Revista Política criminal, vol.4 no.7, Santiago: 2009.

- BASCUÑÁN, Antonio, "La Ley Penal", Revista de Derecho de la Universidad Adolfo Ibáñez, N 2 (2005).

- BERNAL, Jaime y MONTEALEGRE, Eduardo. El Proceso Penal, Bogotá: Universidad Externado de Colombia, 1985, 1990, 2002 y 2004.

- BRASIL, Código Penal.

- BUCHELI DE OSEJO. María Cristina. La detención domiciliaria. Bogotá: Ediciones Jurídicas Gustavo Ibáñez, 1998.

- BUSLOS RAMíREZ, Juan, Manual de Derecho Penal, parte general, Barcelona: 4a ed., 1994

- CEREZo MIR, José, Curso de Derecho Penal Español, parte general, T- II, Madrid: ed. Léenos, 5a ed., 1997.

- Colombia, Código Penal.

- COLOMBIA, Congreso de la República, Ley 1121 de 2006.

- COlOMBIA, Congreso de la República, Ley 1098 de 2008 (Código de la Infancia y la Adolescencia).

- COlOMBIA, Congreso de la República, Ley 1453 de 2011 (Ley de seguridad ciudadana).

- COlOMBIA, Gobierno Nacional, Decreto 177 de 2008.

- COlOMBIA, Gobierno Nacional, Decreto 1316 de 2009

- COLOMBIA, Instituto Nacional Penitenciario y Carcelario (INPEC). Informe Ley 1709 de 2014
- Colombia, Rama Judicial del Poder Público, Corte Constitucional Sentencia C-153 de 1998. MP: Eduardo Cifuentes Muñoz.

- COlOMBia, Rama Judicial del Poder Público, Corte Constitucional. Sentencia C-679 de 1998. MP: Carlos Gaviria Díaz.

- COlOMBIA, Rama Judicial del Poder Público, Corte Constitucional. Sentencia C-184 de 2003. MP: Manuel Jose Cepeda Espinosa.

- COlOMBia, Rama Judicial del Poder Público, Corte Constitucional. Sentencia C-194 de 2005. MP: Marco Gerardo Monroy Cabra.

- COlOMBia, Rama Judicial del Poder Público, Corte Constitucional, Sentencia C-425 de 2008. MP: Marco Gerardo Monroy Cabra.

- COlOMbia, Rama Judicial del Poder Público, Corte Constitucional. Sentencia C-073 de 2010. MP: Humberto Antonio Sierra Porto.

- COlOMBIA, Rama Judicial del Poder Público, Corte Constitucional. Sentencia C-185 de 2011. MP: Humberto Antonio Sierra Porto.

- COLOMBIA, Rama Judicial del Poder Público, Corte Constitucional. Sentencia T-309 de 2012. MP: Jorge Ivan Palacio Palacio.

- COlOMBIA, Rama Judicial del Poder Público, Corte Constitucional. Sentencia T-483 de 2012. MP: Gabriel Eduardo Mendoza Martelo.

- COLOMBIA, Rama Judicial del Poder Público, Corte Suprema de Justicia, Sala Penal, (1012-81), M.P. Alfonso Reyes Echandía.

- COlOMBiA, Rama Judicial del Poder Público, Corte Suprema de Justicia, Sala Penal, Radicado 8539, (13-07-94), M.P. Jorge Carreño Luengas.

- COlOMBiA, Rama Judicial del Poder Público, Corte Suprema de Justicia, Sala Penal, Radicado: 14987 (12-07-00), M.P. 
José Aníbal Gómez Gallego.

- COlOMBiA, Rama Judicial del Poder Público, Corte Suprema de Justicia, Sala Penal, Radicado: 16837 (03-09-01), M.P. José Aníbal Gómez Gallego.

- COlOMBIA, Rama Judicial del Poder Público, Corte Suprema de Justicia, Sala Penal, Radicado 14183 (31-01-02), MM.PP. Jorge E. Cordoba Poveda y Carlos Augusto Gálvez Argote.

- COlOMBIA, Rama Judicial del Poder Público, Corte Suprema de Justicia, Sala Penal, Radicado 19445 (06-10-04), M.P. Álvaro Orlando Pérez Pinzón.

- COlOMBia, Rama Judicial del Poder Público, Corte Suprema de Justicia, Sala Penal, Radicado 21044 (19-01-05), M.P. Jorge Luis Quintero Milanés.

- COlOMBia, Rama Judicial del Poder Público, Corte Suprema de Justicia, Sala Penal, Radicado 23272 (27-08-07), M.P. Sigifredo Espinosa Pérez.

- COlOMBiA, Rama Judicial del Poder Público, Corte Suprema de Justicia, Sala Penal, Radicado 31531 (08-07-09), M.P. Yesid Ramírez Bastidas.

- COlOMBiA, Rama Judicial del Poder Público, Corte Suprema de Justicia, Sala Penal, Radicado 31568 (28-10-09), M.P. Alfredo Gómez Quintero.

- Colombia, Rama Judicial del Poder Público, Corte Suprema de Justicia, Sala Penal, Radicado 29692 (20-01-10), M.P. Alfredo Gómez Quintero.

- COlOMBiA, Rama Judicial del Poder Público, Corte Suprema de Justicia, Sala Penal, Radicado 33655 (07-04-10), M.P. Jorge Luis Quintero Milanés.

- COlOmbia, Rama Judicial del Poder Público, Corte Suprema de Justicia, Sala Penal, Radicado 26916 (04-11-10), M.P. Maria del Rosario González de Lemos.

- COlOMBiA, Rama Judicial del Poder Público, Corte Suprema de Justicia, Sala Penal, Radicado 35943 (22-05-11), M.P.
Julio E. Socha Salamanca.

- COlOMBIA, Rama Judicial del Poder Público, Corte Suprema de Justicia, Sala Penal, Radicado 28143 (29-06-11), M.P. Maria del Rosario González de Lemos.

- Colombia, Rama Judicial del Poder Público, Corte Suprema de Justicia, Sala Penal, Radicado 35512 (27-07-11), M.P. Augusto J. Ibáñez Guzmán.

- COlOMBia, Rama Judicial del Poder Público, Corte Suprema de Justicia, Sala Penal, Radicado 35900 (11-05-11), M.P. Jose Leónidas Bustos Martínez.

- COlOMBIA, Rama Judicial del Poder Público, Corte Suprema de Justicia, Sala Penal, Radicado 34099 (24-02-14).

- COlOMBiA, Rama Judicial del Poder Público, Corte Suprema de Justicia, Sala Penal, Radicado 42623, M.P. Gustavo Enrique Malo Fernández.

- COlOMBia, Rama Judicial del Poder Público, Corte Suprema de Justicia, Sala Penal, Radicado 73770 (29-05-14), M.P. José Luis Barceló Camacho.

- COlOMBia, Rama Judicial del Poder Público, Corte Suprema de Justicia, Sala Penal, Radicado 73914 (25-06-14), M.P. Eugenio Fernandez Carlier.

- COLOMBIA, Rama Judicial del Poder Público, Tribunal Superior de Cundinamarca, Sala Penal, Radicado: 25817-61-01-198-201380171-01 (12-03-14), M.P. Israel Guerrero Hernández.

- CONVENCIÓN AMERICANA DE DERECHOS HUMANOS.

- CUELLO, Eugenio. La moderna penología, Barcelona: Bosch, 1958.

- CURY, Enrique, Derecho Penal, parte general, Santiago: ed. Universidad Católica de Chile, 7a ed., 2005.

- DAIEN, Samuel. Régimen jurídico y social de la libertad condicional. Buenos Aires: Editorial Bibliográfica Argentina, 1947.

- ECUADOR, Código Penal.

- ESPAÑA, Código Penal. 
- ESPITIA, Fabio. Instituciones de derecho procesal penal, sistema acusatorio. Bogotá: Legis, 2010.

- ESTATUTO DE LA CORTE PENAL INTERNACIONAL.

- FERRAJOLI, Luigi. Derecho y razón, Madrid: Trotta, 1997.

- FIERRO-MENDEZ, Heliodoro. La libertad provisional y condicional en el derecho procesal penal, Bogotá: Leyer, 1998.

- __ Manual de derecho procesal penal. Sistema acusatorio y juicio oral y público, Bogotá: Leyer, 2012.

- FOUCAULT, Michel. Vigilar y castigar. Nacimiento de la prisión, México: Siglo XXI Editores, 1983.

- FONTÁN BALESTRA, Carlos. Tratado de derecho penal. Tomo III. Argentina: Editorial Abeledo Perrot S.A, 1995.

- FRANCIA, Código Penal.

- GRUPO DE DERECHO DE INTERÉS PÚBLICO. Situación carcelaria en Colombia. Informe sombra presentado al CHD de Naciones Unidas. Bogotá: Facultad de Derecho. Universidad de los Andes, 2010.

- ITALIA, Código Penal.

- JIMENEZ, Enrique. Derecho procesal penal, Volumen II, Madrid: Revista de derecho privado, 1949.

- JIMÉNEZ DE ASÚA, Luis, Tratado de Derecho Penal, cuarta edición, Buenos Aires: Ed. Losada, 1964.

- LOPEZ BARJA, Jacobo. Tratado de derecho procesal penal, Tomo II, Pamplona: Thomson Reutres Arazadi, 2012.

- LUZÓN, Diego-Manuel, Curso de Derecho Penal, parte general, Madrid: ed. Universitas, 2002.

- MARTÍNEZ, Gilberto. Procedimiento penal colombiano, Bogotá: Temis, 1994, 1997, 2002 y 2006.

- MUÑOZ, Francisco y GARCÍA, Mercedes, Derecho Penal, parte general, Valencia: ed. Tirant Lo Blanch, 7a ed., 2002.

- NOVOA, Eduardo, Curso de Derecho Penal
Chileno, Santiago: Editorial Jurídica de Chile, 1966.

- PABÓN PARRA, Pedro Alfonso. Manual de Derecho Penal. Parte General. Tomo I. Bogotá: Ediciones Doctrina y Ley, 2013.

- PACTO INTERNACIONAL DE DERECHOS CIVILES Y POLÍTICOS.

- POLITOFF, Sergio; MATUS, Jean Pierre; RAMÍREZ, María Cecilia, Lecciones de Derecho Penal Chileno, parte general, Santiago: Editorial Jurídica de Chile, 2a ed., 2004.

- POSNER, Richard. El análisis económico del derecho. México: Fondo de Cultura Económica, 2002.

- PUERTO RICO, Código Penal.

- RAMIREZ, Yesid. Sistema acusatorio colombiano. Bogotá: Doctrina y Ley, 2005.

- REYES ECHANDÍA, Alfonso. Derecho Penal. Parte General. Bogotá: Editorial Temis S.A, 1994.

- RIAÑO VARGAS, Juan Manuel. Informe Estadístico Marzo 2014. Ministerio de Justicia y Derecho

- ROXIN, Claus. Derecho procesal penal, traducción de Gabriela E. Córdoba y Daniel R. Pastor, revisada por Julio B.J.Maier, Buenos Aires: Editores del Puerto, 2000.

- RUBIO, Mauricio. Crimen sin sumario: análisis económico de la justicia penal en Colombia. Documento CEDE 96-04, Bogotá: Universidad de los Andes, 1996.

- RUIZ RENGIFO. Hoover W. Equitipicidad, culpabilidad, preterintención y subrogados penales. Colombia. Ediciones Jurídicas Gustavo Ibáñez C y Ltda. Colombia, 1997.

- RUSCHE, G. y KIRCHHEIMER, O. Pena y estructura. Traducción de Emilio García Méndez. Bogotá: Editorial Temis S.A., 1984.

- URAZAN, Juan Carlos. Lecciones de derecho procesal penal. Bogotá: Leyer, 2002.

- URRUTIA, Hernando y CUESTA, Francisco. Sistema penal acusatorio. Audiencias preliminares y juicio oral, teoría y práctica. Tomo II, Bogotá: Ibáñez, 2008. 